\title{
Variations
}

Variations

Revue internationale de théorie critique

$21 \mid 2018$

L'industrie de la culture : version originale

\section{Kulturindustrie : l'industrie de la culture en tant que modèle critique}

Alexander Neumann

\section{(2) OpenEdition}

Journals

Édition électronique

URL : http://journals.openedition.org/variations/901

DOI : 10.4000/variations.901

ISSN : 1968-3960

Éditeur

Les amis de Variations

Référence électronique

Alexander Neumann, « Kulturindustrie : l'industrie de la culture en tant que modèle critique », Variations [En ligne], 21 | 2018, mis en ligne le 05 avril 2018, consulté le 19 avril 2019. URL : http:// journals.openedition.org/variations/901; DOI : 10.4000/variations.901

Ce document a été généré automatiquement le 19 avril 2019

Les ami•e•s de Variations 


\title{
Kulturindustrie : l'industrie de la culture en tant que modèle critique
}

\author{
Alexander Neumann
}

1 Le mot d'abord. Au début fut le verbe francfortois, explosif, de la dynamite. L'industrie de la culture, ou Kulturindustrie. Plus qu'un mot, il s'agit d'un concept d'un genre nouveau. Sa force critique embrasse pour la première fois des observations empiriques qui touchent à la sociologie et la psychologie de masse, elle actualise la pulsation héritée de la philosophie dialectique, propose une vue internationale et un engagement personnel des chercheurs qui ne se laisse pas neutraliser par les discours scolaires ou positivistes. Le capitalisme global, les bureaucraties d'Etat, leurs idéologies de progrès, les mass média, les formes esthétiques standardisées, sont soumis à une critique dont le versant politique est aussi vif que la charge intellectuelle. Rien ne résiste à ce regard pénétrant, ni les mass médias, la téléréalité, ni la recherche positiviste, ni Facebook, ni Youtube, ni l'audiovisuel public, ni le marché de l'art.

\section{Au début fut le concept}

2 Le présent texte va montrer que l'industrie de la culture est le concept-clé d'une recherche sociale, toujours actuelle, qui, du vivant d'Adorno, est directement intervenue dans la constitution des sciences de la communication américaine, puis française, avant de se déployer à l'échelle planétaire, en réplique à la mondialisation capitaliste. Nous partirons des origines conceptuelles et historiques de l'industrie de la culture, avant de voir son déploiement à travers des générations de chercheuses et de chercheurs, avant de la retrouver en action dans les formes contemporaines de la téléréalité, des réseaux sociaux, des discours préfabriqués, dans les clips et dans la propagande.

Kulturindustrie : l'industrie de la culture. Une traduction qui dit industrie culturelle circule aussi, elle se comprend, mais l'industrie dont il s'agit n'est pas culturelle. Bien au contraire, elle marchande la culture que d'autres ont crée. Si Adorno et Horkheimer avaient voulu parler d'une industrie culturelle, ils auraient pu la nommer kulturelle Industrie et non Kulturindustrie, alors que leurs textes anglais ne parlent jamais de cultural 
industries, mais bien de Culture Industry. ${ }^{1}$ A la suite de Garnham, Bouquillon et Matthews ont précisé que l'usage du terme anglophone creative industries est une émanation directe des théoriciens anglais du New Labour, autrement dit d'un jargon néolibéral qui écarte l'approche de la Théorie critique ${ }^{2}$. Frédéric Martel, qui se passionne pour les boites de production, récuse ainsi le concept d'industrie de la culture, au profit de ces industries créatives qui porteraient si bien leur nom, puisqu'elles seraient justement...créatives, dans une belle tautologie ${ }^{3}$. La preuve que l'auteur nous présente est l'entreprise Disney, qui reproduit la tête de Mickey depuis 1928, cette figurine rongeuse qui s'agite dans des espaces balisés, figure dont Walter Benjamin disait qu'elle symbolise un monde administré, un monde où ce n'est plus la peine de faire des expériences sensibles. ${ }^{4}$ Bien entendu, ce n'est pas Walt qui a dessiné et crée la figure, mais un artiste oublié, Ink Werk.

La Théorie critique permet de comprendre que ce ne sont pas les industries qui sont créatives, ni leur production stéréotypée de masse, mais les sujets vivants qui la nourrissent ou qui tentent de s'y soustraire. Le renversement de sens, qui se joue dans le passage du concept d'industrie de la culture à celui, apologétique, d'industries créatives, se déverse dans une fausse représentation. Celle que Karl Marx a justement exposée, dans un chapitre du Capital consacré au fétichisme de la marchandise. ${ }^{5}$ La circulation généralisée de marchandises, à travers un marché qui tend déjà à se mondialiser, fait oublier l'origine productive et créative des objets qui circulent, que ce soit une paire de chaussures ou un smartphone. Ce mouvement d'abstraction, qui passe par l'échange monétaire, fait passer les marchandises comme les véritables sujets de l'activité sociale, alors que le travail des salariés qui a engendré les marchandises disparait, lui, dans le circuit du capital, qui est en réalité une immense accumulation de travail mort. Sans réseau, l'objet smartphone n'a aucune utilité en soi, alors qu'il apparait comme un sujet de la vie sociale aux yeux des consommateurs. Ce fétichisme explique pourquoi l'industrie se voit attribuée des qualificatifs créatifs, alors que les sujets créatifs et le travail vivant des salariés semblent réduits à une masse inerte de producteurs muets ou de consommateurs contents, repus par l'industrie de la culture. Les soubassements marxiens de cette argumentation sont explicitement sollicités par Horkheimer et Adorno dans le premier manuscrit de La dialectique de la raison (Dialektik der Aufklärung) qui fait apparaitre la Kulturindustrie, même si les citations directes de Marx sont gommés dans la version finale qui est publiée aux Etats Unis ${ }^{6}$. La publication intervient au début de la guerre froide, dans le contexte d'une montée anticommuniste qui obligera Adorno à repartir des Etats Unis.

5 La persistance de cette fausse représentation, qui fait croire que l'industrie serait créative, alors que les créateurs-producteurs seraient passifs, est aussi apparue au détour d'une conférence qu'Oskar Negt prononça à Paris en 2008 à nos côtés, où il évoqua la culture prolétarienne. Les interprètes présents ont choisi de rendre ce concept, qui implique des sujets agissants, par culture "prolétaire", ce qui comporte une caractérisation passive. Le mot culture prolétarienne existe néanmoins en français, puisqu'il s'agit du titre d'un livre de Marcel Martinet, Culture prolétarienne, publié par Maspero. ${ }^{7}$ Le renversement de sens dans l'usage courant des concepts devient ainsi flagrant : l'industrie, elle, serait culturelle, alors que le prolétariat n'aurait pas de lancée active, prolétarienne, mais serait passif, stationnant sur son aire prolétaire. Aujourd'hui, cette fausse représentation s'exprime dans l'idée que le travail vivant des intermittents du spectacle constituerait un coût, alors que les industries qui les emploient créeraient, elles, de la valeur. Les cheminots ou enseignants seraient des privilégiés, alors que les 
rentiers capitalistes des créateurs de valeur entreprenants. Walter Benjamin, Theodor W. Adorno et Max Horkheimer pensaient exactement le contraire, tous ont repris le concept marxien de travail vivant, qui s'oppose au travail mort du capital et ainsi au fétichisme de la marchandise qui, lui, existera tant qu'existera le capitalisme comme forme sociale dominante. Adorno a repris cette filiation conceptuelle de manière très précise dans ses cours universitaires, puis dans le discours d'introduction qu'il prononça en tant que président du congrès de sociologie de 1968 à Francfort-sur-le-Main, au sujet du capitalisme tardif. ${ }^{8}$ Lors de cette conférence, Adorno précise que le capitalisme ne se définit pas par la forme pratique de son industrie, mais par le fait qu'il transforme le travail vivant en marchandise, provoquant ainsi des oppositions de classe, qui se caractérisent par leurs rapports à la production et non pas par leur propre représentation. Cela reste vrai, contrairement à ce que voudrait croire le "bon sens", la communis opinio. Cette opinion publique est justement coiffée par l'effet unificateur des mass médias et l'industrie de la culture. Le penseur francfortois ajoute que cette question ne sera jamais tranchée par la simple documentation de faits, mais relève d'un débat théorique de fond. Le concept d'industrie de la culture nomme ce processus qui transforme les pratiques artistiques, créatives, résistantes en une production de masse qui ne veut connaitre que des marchandises, le marketing des styles similaires et des consommateurs payants.

Le défi est de nature conceptuelle; ainsi la question n'est pas seulement de savoir comment traduire le mot Kulturindustrie, car un éditeur parisien a trouve la solution en gardant le mot en allemand en titre. ${ }^{9}$ Adorno signale lui-même qu'il ne s'agit pas d'une pure affaire littéraire, d'un choix de mots, car il faudrait se garder de définir les concepts de manière positive, comme s'ils devaient figurer dans un dictionnaire ou une encyclopédie. Il voudrait saisir les mots comme des concepts critiques, inassimilables, dans un cadre théorique plus global. Une pointe d'ironie se niche dans l'association des deux substantifs, antinomiques, industrie et culture. En allemand, la composition d'un mot nouveau qui se réalise dans la fusion de deux substantifs peut produire un déplacement de sens, d'un genre dialectique. L'association de cochon (Schwein) et Hund (chien) en Schweinehund ne donne pas le chien du cochon, mais veut dire : salaud! Ventre (Bauch) et sentiment (Gefühl) mis en semble créent Bauchgefühl : l'intuition. Le décalage que produit l'assemblage Kulturindustrie est bien saisie par Martha Rosler qui l'utilise aussi, et qui joue à son tour sur l'association des mots classe et culture, pour invoquer la culture de classe lorsqu'elle évoque la classe de la culture (Culture Class), autrement dit la dénommée classe créative qui aurait remplacé le travail vivant. ${ }^{10} \mathrm{Il}$ est saisissant que les industries de la culture se démultiplient et prolifèrent, au pluriel, dans les discours actuels et en tant que filières économiques, alors que l'usage du concept critique d'industrie de la culture, au singulier, reste disputé, marginalisé. Les industries de la culture tentent de s'emparer de la notion même d'industrie de la culture.

\section{L'industrie de la culture en tant que programme de recherche sociale}

7 Développer le modèle critique d'industrie de la culture signifie d'entrer dans une sociologie des médias qui ne place pas les médias en son centre, pour reprendre une formule d'Oskar Negt. Pareille approche se fonde sur une critique globale du capitalisme tardif. 
8 Malgré le foisonnement des publications classiques et nouvelles, la cohérence des recherches sociales qui portent sur l'industrie de la culture risque d'être minorée dans la discussion intellectuelle, dans des lectures qui se contentent de constater le caractère fragmentaire des écrits francfortois. L'essai libre et l'écriture fragmentaire, qui résistent à la normalisation académique ou médiatique, correspondent à un choix stylistique volontaire de la part de Horkheimer et Adorno; le sous-titre de leur Dialectique de la Aufklärung évoque ainsi des "fragments philosophiques", mais cela ne doit pas être pris pour une forme de dispersion. D'autant que ces éléments convergent plus tard chez Adorno, dans son ouvrage magistral, La dialectique négative. ${ }^{11}$ Même cette reconstitution, nécessaire, reste insuffisante. Les lectures purement philologiques ou philosophiques des textes fondateurs ne peuvent suffire à reconstituer la cohérence globale du mouvement critique qui s'exprime, aujourd'hui encore, de manière vivante et qui cherche à abolir la philosophie traditionnelle.

9 Ici, nous cherchons à préciser la cohérence, la continuité et la dynamique d'ensemble qui a permis la construction du modèle critique qui s'exprime dans le concept d'industrie de la culture. L'interprétation qui va suivre part d'un grand nombre de recherches empiriques et de l'intégralité des textes publiés qui sont liés au concept dont il s'agit. Elle se fonde sur les correspondances historiques, théoriques et sociologiques qui se font jour dans le déploiement de la Théorie critique. Afin de saisir le programme critique qu'elle développe, à l'échelle internationale, le présent article examine les écrits les plus siginficatifs depuis 1923, en partant des textes originaux dans les trois principales langues qui les portent (Allemand, Anglais, Français), le tout dans une optique transdisciplinaire. L'approche est renseignée par nos propres recherches depuis 1999, dont un séjour de recherche aux archives Adorno et Benjamin à Berlin en 2015, et par nos échanges directs au cours de la même période, notamment avec Oskar Negt, Alexander Kluge, Christine Morgenroth, Micha Brumlik, Alex Demirovic du côté francfortois, avec John Holloway, Frederic Jameson, Nancy Fraser, Martha Rosler dans l'espace anglophone, avec JeanMarie Vincent, Michael Löwy, Miguel Abensour, Lucia Sagradini, Arno Münster, Jan Spurk, Yves Sintomer et Michèle Riot Sarcey du côté parisien, sans oublier les discussions actuelles avec mes collègues du cemti à l'Université Vincennes - Paris 8.

10 L'interprétation que je propose va faire converger les recherches empiriques et leurs conceptualisations critiques, vers l'analyse de la stéréotypie qui apparait à la fois comme un concept-clé et comme un carrefour des apports philosophiques, esthétiques, psychologiques et sociologiques, par lequel transitent aussi les études médiatiques.

11 La dimension de la stéréotypie touche ainsi différents domaines d'investigation de la Théorie critique qu'il devient alors possible de relier : la stéréotypie des standards culturels, musicaux ou cinématographiques de l'industrie de la culture allemande et hollywoodienne; la stéréotypie des discours de propagande qui sont formatés et diffusés à travers les mass médias à l'instar de la radio; la stéréotypie des préjugés autoritaires et identitaires, par exemple racistes, qui répond à des simplifications idéologiques, surtout en période de crise, mis à jour par les études sur la personnalité autoritaire; la réception de ces schémas et stéréotypes qui se joue à travers les feuilletons télé ou aujourd'hui la téléréalité; la stéréotypie des formes esthétiques et de la régression de l'expérience sensible.

12 Les différents apports apparaissent de manière dispersés et partielle dans le débat francophone, ce qui n'est pas seulement dû aux traductions incomplètes et aux publications tardives, mais surtout à la méconnaissance des grandes recherches 
empiriques, sociologiques et socio-psychologiques qui ont directement nourri les conceptualisations critiques qui font éclore le modèle de Kulturindustrie. Cela touche notamment au désaccord de fond avec la sociologie de Lazarsfeld. C'est la raison pour laquelle j'ai choisi une entrée historique susceptible de renouer le fil rouge du développement conceptuel. La périodisation suit les grandes étapes des recherches de l'Institut de Francfort, à travers sa création initiale, l'exil, le retour en Europe, puis la relance du modèle critique sur un plan international. Si notre interprétation, qui focalise le regard sur la stéréotypie et son dépassement possible, mobilise de nombreux auteurs qui ont participé à la formation de la Théorie critique, les textes les plus marquants d'Adorno vont nous servir de fil rouge. Le principe de ces recherches est mu par la dialectique de l'expérience et du concept.

\section{Temps historiques, hier et aujourd'hui}

La construction transdisciplinaire qui a conduit à la formulation du concept d'industrie de la culture se produit ainsi en plusieurs temps qui sont ici esquissés avant d'exposer le développement de manière plus touffue :

14 - D'abord, les prémisses du modèle critique apparaissent dès la naissance de la Théorie critique qui se manifeste en 1923 autour de la fondation de l'Institut de recherche sociale de Francfort, à travers son programme, puis dans l'essai de Max Horkheimer qui distingue les théories traditionnelles de la Théorie critique. Cette année là, Adorno, Benjamin et Kracauer font connaissance dans un Café francfortois.

15 - Puis, le modèle critique prend corps sur un plan empirique, grâce à la réalisation des premières enquêtes que l'Institut lance au début des années 1930 dans la République de Weimar, à commencer par une grande enquête encore méconnue sur les attitudes des ouvriers et employés allemands à la veille du 3ème Reich, conduite par Erich Fromm. Cette étude est entourée des essais de Walter Benjamin l'art et les mass médias, et celle de Siegfried Kracauer sur le cinéma. L'ensemble de ces travaux nourrissent le programme de recherche sociologique qu'Adorno formule à travers ses échanges avec Paul Lazarsfeld en 1938.

16 - Ensuite, cette rencontre permet le lancement de plusieurs projets de recherche empiriques aux Etats Unis qui concernent tour à tour la radio, la télévision, l'industrie cinématographique, ainsi que l'analyse du rapport entre l'opinon publique, les préjugés et l'adhésion à l'autorité. Ces études interviennent directement dans l'écriture du chapitre consacré à l'industrie de la culture qui se trouve dans $L a$ dialectique de la raison, que Horkheimer et Adorno écrivent à quatre mains. Les études sur la personnalité autoritaire, qui s'inscrivent dans la prolongation d'une série d'enquêtes sur les médias américains, et la thèse de l'industrie de la culture peuvent être lues dans une seule et même dynamique. Je souhaite mettre en relief comment la production et la diffusion des standards de masse, par l'industrie de la culture, répond à l'acceptation de jugements schématiques reçus par divers publics, qui sont scrutés dans les études sur la personnalité autoritaire. Bien entendu, ce type d'attitude, en proie au jugement stéréotypé, est contre-balancée par plusieurs autres types de personnalité, plus démocratiques, au sein de la société globale.

17 - Cet élan de recherche se poursuit de retour en Allemagne à partir de 1953, notamment à travers des enquêtes encore méconnues sur la manifestation de préjugés en entreprise, puis la précision de la thèse de l'industrie de la culture en tant que schéma de la culture de masse (publiés en 1969), et la formation des typologies sociales qui y correspond. À 
partir de 1958, des invitations d'Adorno à Paris, par Lucien Goldmann ou George Friedman, vont influencer la revue Communications et son entourage sociologique, puis les travaux d'Edgar Morin ou de Pierre Bourdieu.

18 - Après la mort d'Adorno, en 1969, les thématiques de recherche sociologiques sont relancées, actualisées et étendues sous la nouvelle direction de l'Institut de recherche sociale qui est assurée Gerhard Brandt jusqu'en 1987, en l'absence d'Habermas qui ne joue aucun rôle dans ce développement francfortois. ${ }^{12}$ Les principales enquêtes de l'institut, jamais citées dans l'espace francophone, portent sur l'automation et l'informatisation, l'internationalisation de la production flexible, la féminisation et l'érosion de l'espace public bourgeois.

19 - Pendant ce temps, la thématique de l'expérience, des médias et de l'industrie de la culture est poursuivie de manière explicite par Oskar Negt, disciple d'Adorno, à Hanovre, aux côtés d'Alexander Kluge, puis dans de nombreux centres de recherche sur les cinq continents du globe. Aujourd'hui, l'approche est par exemple présente à la New School de New York, à la faculté de Beijing, à Sao Paolo ou encore à l'Université Paris 8.

Les parties qui vont se succéder ici veulent saisir les fondements, temps et contre-temps du développement du modèle critique de la Kulturindustrie : impulsions; conceptualisation; approfondissement; extensions; mondialisation.

\section{Impulsions. Francfort - Berlin - New York (1923-1938)}

21 Commençons l'exposé de la formation du modèle critique de la Kulturindustrie par les études préliminaires, précoces, qui vont éclore à partir de 1923 pour permettre l'émergence explicite du concept d'industrie de la culture au début des années 40 . En 1923, année de création de l'Institut de Francfort, se rencontrent pour la première fois Adorno, Kracauer et Benjamin, dans un Café de la ville. Tous les chercheurs francfortois partagent une même expérience de la crise, celle qui déchire l'Europe entière depuis la première guerre mondiale, qui n'est arrêtée que par la révolution des conseils russe, puis allemande. L'entre-deux guerres est marqué par l'hyperinflation allemande, des tentatives de coup d'Etat nationalistes, la crise économique de 1929 et la montée du fascisme. Le programme de recherche initial de l'Institut de Francfort, rédigé en 1922 par Joachim Gerlach prévoit d'analyser les phénomènes suivants : "Grève de masse, sabotage, vie internationale du syndicalisme, analyse sociologique de l'antisémitisme, bolchévisme et marxisme, parti et masse, mode de vie des différentes couches de la société ". ${ }^{13}$

Si la référence à la grève de masse et aux mouvements subversifs rappelle la révolution allemande des conseils de 1918 qui a finalement débouché sur la république de Weimar, l'analyse sociologique de l'antisémitisme et celle des modes de vie signale l'attention particulière qui est portée aux préjugés et attitudes sociales. Les chercheurs proches de l'Institut de Francfort se sont distingués par les premières études sur les employés (Kracauer), au sujet de l'attitude politique des ouvriers (Fromm), ${ }^{14}$ repris plus tard sous le leitmotiv d'études sur La conscience ouvrière en temps de crise par Rainer Zoll, actualisé par Bodo Zeuner et d'autres. ${ }^{15}$ En 1933, ces premières études sont complétés par une sociographie sur les chômeurs de la région de Vienne, conduite par Paul Lazarsfeld et alli, qui indiquent alors une affinité sociologique qui va plus tard favoriser à la coopération directe de Lazarsfeld et Adorno pendant l'exil. 

compréhension de la formation des stéréotypes, l'un des aspects décisifs de l'industrie de la culture. Pour saisir ces enjeux, la recherche francfortoise part des phénomènes marquants de son temps. Kracauer publie le premier livre sur le mode de vie des employés berlinois, leurs organisations et leur culture de masse. Il scrute en même temps la production cinématograhique, caractérise son appareil UFA qu'il décrira plus tard comme un prototype de l'industrie de la culture hollywoodienne, alors qu'il développe déjà ce qu'il appelle "l'analyse structurale" des films diffusés en salle. ${ }^{16}$ La méthode et les tableaux comparatifs de l'analyse structurale sont publiées en 1947, bien avant la L'anthropologie structurale de Lévi-Strauss et les analyses structuralistes françaises qu'il inspire. L'apport critique initial est honoré par Michel Foucault en 1978 par un hommage vibrant à Horkheimer et Adorno, lorsqu'il souligne qu'il aurait du les lire "bien avant" et de les comprendre plus tôt : "Si j'avais lu ces œuvres, il y a un tas de choses que je n'aurais pas eu besoin de dire et j'aurais évité des erreurs ". ${ }^{17}$ S'il est évident que le structuralisme français a connu son propre développement, qui aboutit à la mort du sujet, il ne gagnerait pas moins à être relu dans une perspective internationale et transversale. Le corpus que Kracauer choisit d'analyser est constitué par les films expressionnistes allemands qui lui permettent de percevoir les thématiques traumatiques, l'angoisse et le malaise des spectateurs, dont une partie significative va adhérer au national-socialisme dès le début des années 1930, sachant que ces études ne seront publiés que pendant son exil aux Etats-Unis. Kracauer montre aussi, en 1927, avant la rédaction de La dialectique de la raison, que les masses ne sont pas nécessairement guidées par la raison, sous la république, et que des éléments mythiques peuvent être mobilisés par les médias de masse, dans Das Ornament der Masse. ${ }^{18}$ Cette intuition juste sera explicitée par Horkheimer et Adorno dans leur chapitre sur les mass médias en tant que tromperie en masse, qui montre, dans La dialectique de la raison, comment l'apparente raison se retourne en mystification. Dans le livre, la relation qui unit le mythe ancien et la rationalité moderne est illustrée par le voyage d'Ulysse, où sa maitrise des forces de la nature s'accompagne de l'imposition d'un rapport de domination de l'homme sur les hommes. Plus tard, Negt et Kluge vont élargir cette réflexion par un commentaire sur Jason et les argonautes.

Par le même biais du détournement de la raison dans les masses, Kracauer thématise la psychologie de masse, un concept qui est clairement exposé par Freud dans Psychologie de masse et analyse du Moi, et repris dès 1933 par Wilhelm Reich dans son livre La psychologie de masse du fascisme. ${ }^{19}$

Poussant plus loin cette problématique, Erich Fromm développe les concepts de Freud au sujet de la formation des personnalités et la psychologie de masse, dans un article du journal de l'Institut de Francfort paru en 1932, qui jette les bases d'une étude systématique des types de personnalité, dite caractérologie sociale. ${ }^{20}$ Cet article érudit fait partie de la base théorique des Etudes sur la personnalité autoritaire qui seront menées aux Etats-Unis à une grande échelle. Fromm ne se contente pas de traduire les concepts freudiens de la psychologie de masse vers la socio-psychologie et la sociologie, mais il va lui-même lancer la première enquête empirique sur Les attitudes des ouvriers et employés allemands en temps de crise, dès 1929. ${ }^{21}$ Cette enquête, dont les premiers résultats n'ont pu être publiés qu'au cours de l'exil, est menée auprès de plusieurs milliers de personnes, sur la base d'un questionnaire unique. La version allemande complète du rapport fut éditée en 1980. A cause des difficultés matérielles qui sont du aux circonstances, Fromm ne peut prétendre à une représentativité exacte des échantillons, mais il découvre néanmoins des 
tendances qui vont s'avérer assez justes, sur la base d'environ mille questionnaires complétés. En dépit du fait qu'une majorité des personnes se déclarent électeurs ou sympathisants des syndicats et partis de gauche, il montre qu'environ $15 \%$ seulement des personnes interrogés se distinguent par une attitude démocratique cohérente, ce qui lui fait comprendre dès 1930 que l'opposition aux mouvements autoritaires ou fascistes est beaucoup plus faible que la représentation parlementaire de gauche pourrait le faire croire.

Cette étude est complétée par d'autres enquêtes menées de concert par Horkheimer, Fromm et Marcuse, avec l'appui d'une série d'autres chercheurs francfortois au sujet du rapport entre l'autorité et la famille, qui est bouclée en 1933 et publiée dans l'exil parisien en 1936. Horkheimer y fixe l'orientation critique globale, Fromm définit le contexte sociopsychologique, Marcuse situe le sujet dans l'histoire des idées. Les auteurs décèlent les effets anti-démocratiques d'une éducation autoritaire qui remonte à l'époque impériale, mais qui se trouve mise en question par le divorce, le changement de la morale sexuelle, l'adolescence et la libération sexuelle potentielle que contiennent les mouvements de jeunesse. Ce constat est publié à Paris, un demi siècle avant que le mouvement du 22 mars 68 ne mette le feu aux poudres, face à la séparation des dortoirs et la misère en milieu étudiant. Les préjugés moralistes, autoritaires et sexistes sont au centre de cette analyse francfortoise, qui préfigure les Etudes sur la personnalité autoritaire, en saisissant le lien entre socialisation autoritaire et disposition au préjugé. Fromm participera aux débuts de cette vaste recherche que l'Institut de Francfort, alors réfugié à New York, conduira pendant les années 1940, et son article de 1932 sur la caractérologie sociale va continuer à marquer les textes d'Adorno, y compris celles qui abordent les études sur le préjugé et le caractère social (la personnalité) dans les années 1950 et 60, à son retour d'exil.

Une autre source critique de la formulation du concept d'industrie de la culture se trouve dans les travaux de Walter Benjamin, qui ne participe pas aux recherches empiriques de l'Institut, en particulier les écrits et essais qu'il écrit pendant sa période parisienne, jusqu'à sa mort en 1940. Parmi les essais benjaminiens les plus marquants de cette période compte son texte sur L'oeuvre d'art à l'époque de sa reproductibilité technique, à côté des Thèses sur l'histoire et Paris, Capitale du XIXème siècle. ${ }^{22}$ Benjamin aborde directement les nouvelles possibilités techniques et esthétiques qu'offre la reproduction en masse des images, en particulier le cinéma, qui sera ensuite au centre des réflexions de Horkheimer et Adorno face à la production hollywoodienne. Les désaccords théoriques entre Benjamin et Adorno nourrissent une correspondance intellectuelle dense, qui déplace sans cesse les points de vue réciproques des deux amis. L'un des points de tension est la question de savoir jusqu'à quel degré l'accès en masse à la culture renferme un potentiel émancipateur. Adorno souligne la nécessaire contemplation pour recevoir le sens d'une oeuvre, opposée au divertissement standardisé, alors que Benjamin conçoit la réappropriation collective d'une oeuvre cinématographique en salle, à travers l'action des spectateurs, susceptibles de sauver l'oeuvre par leur regard critique. Vers la fin de son essai, Benjamin propose une mise en perspective fédératrice, au vu de la tension qui oppose la contemplation au divertissement, en affirmant dans sa dernière thèse: "Le public est un évaluateur, mais d'un genre distrait"(nous traduisons). ${ }^{23}$ Adorno garde en tête le risque d'une propagande autoritaire en masse, qui est très tôt pratiquée par le régime nazi d'Hitler via la radio (fonction de propagande qu'il ira analyser en live aux USA), alors que Benjamin souligne les possibilités révolutionnaires du cinéma par la liberté nouvelle de sa forme esthétique, à l'exemple des films de Serguei 
Eisenstein. Le public populaire a le moyen de se reconnaitre dans les scènes, à l'instar de la foule révolutionnaire filmée par Eisenstein, composé de figurants qui ressemblent culturellement au public prolétarien qui va découvrir la scène en salle, capable d'annuler l'effet fétichiste du mass média par un acte de reconnaissance, une critique salvatrice. Il finit par discerner très clairement les optiques politiques en jeu, lorsqu'il conclut, en 1936, que le fascisme promeut l'esthétisation de la politique, alors que ses opposants cherchent à politiser l'art. ${ }^{24}$ Dans l'une de ses dernières lettres à Adorno, qui date de mai 1940, Benjamin s'adresse au "cher Teddy" avec ces mots :

J'ai relu les passages sur l'écoute régressive auxquels vous me renvoyez et j'ai constaté que tendanciellement nos recherches concordaient. (...) Il m'étonnerait d'ailleurs que vous ayez raison en vous représentant comme vous le faites ce que je pense de votre travail sur le caractère fétichiste. ${ }^{25}$

Adorno ne cessera plus de réfléchir aux désaccords partiels (le Jazz) et surtout les accords théoriques de fond qui sont inscrit dans ces échanges, notamment à travers un écrit jamais achevé qui devait porter sur les formes stéréotypées de la musique. Arrivé en exil aux Etats-Unis, en 1938, il va commencer par examiner les formes stéréotypées des discours médiatiques et de l'opinion publique au sein du Princeton radio research project.

\section{Conceptualisation. De New York à Hollywood (1938-1944)}

31 Avec l'arrivé d'Adorno à New York, ce sera surtout sa rencontre entre avec Paul Lazarsfeld qui va marquer la recherche sociale liée à la Théorie critique. Nous avons déjà pointé la proximité thématique, temporelle et méthodologique des premières enquêtes ouvrières de Kracauer ou de Fromm d'une part, l'étude sur les chômeurs de Lazarsfeld et alli d'autre part, au début des années 1930. A partir du début de l'année 1938, Adorno va nouer un fil sociologique à travers sa correspondance avec Lazarsfeld, en proposant sa collaboration aux enquêtes américaines que le sociologue a commencé à mettre en place d'une manière strictement académique. Adorno maintient l'intégralité des connaissances de la Théorie critique, et souligne à cette occasion que cela implique pour lui de partir de l'expérience, afin de permettre "une interaction entre la théorie et les recherches empiriques que nous appelons la méthode dialectique. Je suis ravi que vous partagiez ce point $\mathrm{du}$ vue dans votre dernière lettre". ${ }^{26}$ Cette position éclaire la dialectique de l'expérience et du concept qui fonde le modèle critique d'industrie de la culture. Lazarsfeld, sociologue universitaire bien établi qui tient tout de même à marquer sa distance envers la radicalité critique d'Adorno, lui confie alors la direction du secteur de recherche "musique" au sein du Princeton radio research project plus large dont il a la responsabilité. ${ }^{27}$ Adorno se jette dans le travail d'enquête, il analyse notamment le courrier des lecteurs des grandes stations de radio pour cerner les opinions spontanées et les gouts de auditeurs et pour analyser des émissions, musicales avant tout. ${ }^{28}$ L'équipe de recherche de ce projet analyse aussi la réaction des auditeurs américains à la diffusion de l'émission radio La Guerre des mondes, qui fait croire à une attaque d'extraterrestres en live, un soir d'Halloween. Le projet évalue ensuite à plus de six millions le nombre d'auditeurs dont $25 \%$ ont spontanément cru qu'il s'agissait d'un reportage véridique en temps réel.

32 L'expérience nouvelle que Adorno acquiert entre 1938 et 1940 au sein de la sociologie américaine aiguise son esprit, juste avant d'entamer la rédaction de La dialectique de la 
raison aux côtés de Horkheimer, à la suite de cette période. L'enquête pratique sur les formes stéréotypées des contenus diffusés par la radio précède ainsi la formulation conceptuelle de l'industrie de la culture.

L'expérience sociologique d'Adorno lui permet finalement de définir de manière bien précise les limites de la recherche universitaire que pratique Lazarsfeld, soucieux de fournir des critères d'analyse et de gestion aux politiques publiques des USA, qui enferment les questions de départ dans un monde administré. Alors qu'Adorno et d'autres chercheurs d'inspiration francfortoise veulent faire apparaitre les clichés récurrents et les impensés autoritaires des médias de masse, à partir d'une intention critique, Lazarsfeld s'oriente vers ce qu'il appelle "la recherche administrative et communicationnelle", qui s'arrête à une forme d'objectivité qui tend à reproduire les normes établies. Le désaccord programmatique, qui n'oppose en rien sociologues et profanes non-scientifiques mais qui dessine une ligne de clivage au sein des sciences sociales, se manifeste dans un "mémorandum de recherche" qu'Adorno rédige en 1941 à l'attention de Lazarsfeld et que le dernier refuse. ${ }^{29} \mathrm{La}$ recherche empirique oui, l'orientation critique des méthodes et concepts non, pourrait-on résumer sa position.

Adorno insiste notamment sur le fait que la recherche empirique ne doit pas s'épuiser dans des appareils scientifiques formels, mais qu'elle doit se concentrer sur des problématiques pointues qui promettent de concrétiser les perspectives de la Théorie critique. Lazarsfeld, lui, entend surtout consolider une recherche administrative et communicationnelle (adminstrative and communicationnal research) pour les institutions qui sert à cerner la pertinence de critères d'analyse et de gestion, à un moment où les besoins de propagande pour soutenir l'entrée en guerre des USA devient un sujet urgent. Lazarsfeld accepte volontairement des commandes publiques et privées, financées par des grandes administrations ministérielles et des entreprises, afin d'enquêter sur la manière dont différents groupes sociaux reçoivent des messages politiques ou publicitaires. Cette visée favorise l'adhésion, alors qu'Adorno cherche à développer la distance critique, le doute. Aussi, Lazarsfeld axe ses recherches sur des analyses statistiques et quantitatives, alors que l'approche de la Théorie critique insiste depuis ses débuts sur l'aspect qualitatif, en lien avec l'expérience singulière des citoyens. Cette confrontation des points de vue va fournir des arguments théoriques qu'Adorno déploiera davantage après la guerre, au cours de la querelle au sujet du positivisme, à l'encontre de Popper..$^{30}$

35 Immédiatement après la rédaction de la première version complète de la Dialektik de la Aufklärung, en 1944, Adorno va réaliser le programme de recherche empirique et critique qu'il appelle de ses voeux, en prenant la co-direction scientifique du grand projet des études sur la personnalité autoritaire, aux côtés du socio-psychologue Nevitt Sanford de l'Université de Californie. L'institut d'origine francfortoise s'approche encore davantage de L.A. et de sa banlieue Hollywood.

36 A ce moment précis, l'argumentation de Horkheimer et Adorno au sujet de l'industrie de la culture a pris corps, elle se manifeste dans un chapitre de la Dialectique de la raison qui s'intitule : "Kulturindustrie. Aufklärung als Massenbetrug" et que nous traduisons par "L'industrie de la culture. La Aufklärung en tant que tromperie en masse".

37 L'industrie de la culture organise la reproduction et la standardisation de produits culturels sous la forme de styles imitables et reproductibles, tout comme l'industrie automobile assure la production en série et en masse de voitures ou d'autres marchandises. L'exemple que donnent Horkheimer et Adorno est le principe Ford et 
l'entreprise automobile General Motors, qu'ils comparent à la boite de production Warner Brothers. $^{31}$

Les auteurs insistent sur le fait que cette industrie désigne un principe de fonctionnement du système économique, le capitalisme, et non pas un simple phénomène technique. Que ce soit pour l'achat d'un disque de musique, d'un ticket de cinéma ou d'une voiture, la consommation participe d'un fétichisme de la marchandise qui s'étend ainsi sur toute la société, y compris la culture et la communication, à travers les mass médias. La tendance totalisante de ce modèle de massification, qui va du fordisme productif à la communication de masse, menace donc directement l'individu, l'autonomie et l'espace public, compris comme une sphère qui ne soit pas soumis au principe marchand ou bureaucratique. Voilà comment la raison et la rationalisation qui sont nés avec les promesses d'émancipation des Lumières se retournent en une domination qui se double d'une représentation fétichiste et spectaculaire.

\section{Approfondissement. Californie, L.A., Hollywood (1944-1951)}

39 La période californienne noue différents aspects de l'analyse sociologique de la stéréotypie, qui nous intéresse particulièrement, dans le but de saisir la cohérence du modèle critique d'industrie de la culture. Dans son analyse des séries télé et de films hollywoodiens, Adorno décrit explicitement le caractère stéréotypée de cette production audio-visuelle. La pauvreté volontaire des scénarii entre en résonance avec la rigidité des schèmes idéologiques et "la stéréotypie" des feuilletons. L'industrie de la culture la justifie par les contraintes commerciales et techniques de la production, ainsi que par la demande du jeune public, une thématique encore actuelle ${ }^{32}$. Cette étude n'est réalisée qu'après la publication de La dialectique de la raison et des Etudes sur la personnalité autoritaire, qui, elles cernent le rôle de la stéréotypie dans les attitudes de différents publics et groupes sociaux, et leur perméabilité à des discours préfabriqués ou autoritaires. L'usage du terme de stéréotypie permet de montrer comment les différentes recherches sur l'industrie de la culture et la socialisation des publics qui ont lieu pendant la même période s'épaulent et s'enrichissent mutuellement.

L'originalité scientifique du projet de recherche Les études sur la personnalité autoritaire qui démarre en 1944, le caractère innovant de sa méthodologie et sa dimension critique, tournée vers l'analyse en profondeur des ressorts des préjugés et le degré d'adhésion à l'autorité établie, ne font alors aucun doute. ${ }^{33}$ Les publics visés sont très variés: des ouvriers, des employés, des étudiants ou encore des femmes au foyer, contactés grâce au concours des syndicats et des associations concernées. La recherche initiale repose sur un soubassement théorique et clinique, qui motive une méthode particulière, associant la construction d'un questionnaire indirect à la réalisation d'entretiens qualitatifs. 2099 personnes ont été directement interrogées au cours de l'enquête, sur la base d'un questionnaire, enquête doublée de plus de 200 entretiens individuels approfondis, ainsi que de discussions en petits groupes qui sont animés par les chercheurs, afin de vérifier la compréhension exacte des réponses données.

41 L'enquête s'organise autour d'un questionnaire d'un nouveau type, dont la construction et l'exploitation est soutenue par des entretiens individuels longs, ainsi que des discussions de groupe. Comme nous l'avons souligné dans la section précédente, 
l'approche entend distinguer et séparer les attitudes fondamentales (le caractère social) d'un côté, et les simples opinions énoncés, de l'autre. Les questionnaires se composent d'affirmations en apparence anodines qui se succèdent indistinctement. La proposition numéro 41, par exemple, soumet le constat suivant à l'appréciation des personnes interrogées : "Les entrepreneurs sont beaucoup plus importants pour la société que les artistes et les professeurs"; la proposition 37 affirme "Si les gens travaillaient plus au lieu de parler, tout le monde se porterait mieux". ${ }^{34}$ Pareilles propositions, qui cherchent à saisir l'attitude sociale "conventionnelle", qui est cernée à l'aide d'une série d'autres propositions, une attitude qui s'avère particulièrement répandue dans la petite bourgeoisie. D'autres groupes d'affirmations, à côté du conventionnalisme, concernent la soumission à l'autorité, l'agression contre la déviance et le rejet des outsiders, la réaction défensive contre l'imaginaire et la subjectivité, la superstition, l'exhibition du pouvoir et de la virilité, les tendances paranoïaques, ainsi que l'obsession sexuelle. Ces thématiques sont ainsi évaluées par des séries de propositions qui forment des groupes typologiques, mais elles se succèdent dans un désordre apparent au sein du questionnaire, aux yeux des personnes enquêtées. Le questionnaire intégral est reproduit en annexe de la publication originale du rapport.

Les traits de caractère dominants révélés par ce type d'enquête esquissent la structuration psychologique des personnalités interrogées, permettant de construire une typologie sociologique complexe. Elle diffère des catégorisations de la psychologie universitaire traditionnelle dans la mesure où ce ne sont pas des réactions individuelles qui sont examinées, mais les traits de socialisation. Si le titre du livre évoque la personnalité autoritaire, le rapport décrit en réalité un champ de lutte entre différents types bien distincts de personnalité, qui se retrouvent dans des attitudes sociales caractéristiques. Les attitudes ethnocentriques, antisémites et racistes, cumulent par exemple chez le type de personnalité le plus autoritaire, dont le comportement politique pourrait facilement s'accorder avec une mobilisation nationaliste, sinon fasciste. Cette analyse indirecte cerne bien mieux les tendances antidémocratiques des individus concernés que les enquêtes d'opinion actuelles, destinées à évaluer la diffusion des idées racistes à partir de questions explicites, par exemple au sujet de la "préférence nationale". L'enquête sur la personnalité autoritaire formule des questions dont les réponses permettent aux personnes interrogées de se considérer comme des démocrates, tout en leur permettant d'exprimer des préjugés s'ils le souhaitent. ${ }^{35}$ Les réponses des personnes interrogées sont ensuite synthétisées et classées sur une échelle, dite "échelle F" comme fascisme, qui décrit plus précisément la disposition latente de la personne pouvant favoriser une adhésion au discours fasciste ou autoritaire. Cette échelle est complétée par deux autres, portant sur le degré d'autoritarisme (échelle A) et d'ethnocentrisme (échelle E). Chaque questionnaire et l'échelle à laquelle celui-ci correspond a été remanié trois fois, grâce aux premiers résultats, grâce aux entretiens qualitatifs et aux discussions du groupe des chercheurs et enquêteurs, avant de trouver finalement sa forme appropriée, dans une sorte de boucle de rétroaction. ${ }^{36}$ Parmi les considérations contemporaines, certaines cherchent à peaufiner la méthode d'enquête, d'autres la simplifient et encore d'autres voudraient la remplacer par une simple analyse statistique d'un genre positiviste, sans que cette dernière approche apporte des résultats concluants.

43 Le constat central de la grande enquête que nous abordons est la très faible variation des dispositions autoritaire entre les différents groupes sociaux observés (ouvriers, ouvrières, 
employés, étudiants, hommes ou femmes des classes moyennes, etc.), à un niveau statistique global. Le fait est que les dispositions autoritaires ne sont pas moins ou plus répandues chez les ouvriers américains que chez les hommes appartenant aux classes moyennes et qui fréquentent des salons. En revanche, si on met de côté cette moyenne très générale, la différence est assez forte en fonction de milieux plus précis. Ainsi, la disposition autoritaire dépasse nettement la moyenne globale chez les anciens ouvriers incarcérés dans la prison St. Quentin, alors qu'elle est particulièrement faible chez les hommes de Los Angeles qui participent à des cours de formation syndicale. Le mode de socialisation, influe donc fortement sur la disposition, autoritaire ou au contraire démocratique, des personnes concernées.

Les mêmes phénomènes de socialisation générale et de différenciation culturelle en fonction des parcours se manifeste aussi dans la consommation de séries télé qu'Adorno analyse à la suite de la publication du rapport de 800 pages sur la personnalité autoritaire, qui regroupe de nombreux auteurs. L'édition américaine complète de 1950 se présente en cinq volumes. ${ }^{37}$

Ce sont les études sur la personnalité et le préjugé, qui servent de base aux études sur la télévision qu'Adorno conduit, ensuite, jusqu'en 1953, en tant que directeur scientifique de la Hacker Foundation. Elles donnent lieu à la rédaction de nouveaux articles qui ne se contentent pas d'exposer les résultats de cette étude qui se sert de manuscrits de scénarii hollywoodiens, répétitifs à souhait, mais qui s'inscrivent dans la formulation de ses "modèles critiques", à la manière de l'essai La télévision en tant qu'idéologie ou de son prologues sur la TV..$^{38}$ Interrogé plus tard par une radio de Vienne, en 1969, Adorno se souvient que les soap opéras américaines de distinguent par leur manque d'esprit, à la manière de ce feuilleton qui met en scène un bon médecin de campagne et une infirmière qui volent sans cesse au secours de braves gens en difficulté, une peine qui rappelle celle de la ménagère qui est supposée suivre de tels récits. Portée par la concentration des pouvoirs économiques qui se produit dans les mass médias, l'industrie de la culture se déploiera au grand jour, et se montrera pour ce qu'elle est en réalité, une régression, ditil alors ${ }^{39}$. Les scénarii TV qu'Adorno étudie aux Etats Unis viennent des maisons de production de Beverly Hills, qui se situent un peu au-dessus du standard moyen, mais encore en dessous de ce que permet le cinéma de masse. Le format qui n'excède pas une demi heure plombe la qualité de la narration : "Même la marge que le film offre au développement du récit et des personnages est supprimée; tout doit être clair tout de suite. (...) La ressemblance avec les longs-métrages témoigne l'unité de l'industrie de la culture, la question de savoir où on la saisit importe peu". Nous l'avons signalé en introduction au présent texte, ces études permettent de saisir le caractère stéréotypé, puissant, des feuilletons de télévision, qui ont porté le personnage de téléréalité Trump. Bien entendu, le penseur critique en exil voit la possibilité technique et pratique de diffuser des programmes plus élaborés ou critiques, mais il constate que la pression conformiste de la production capitaliste, de la vente en masse en direction d'un public très large et des normes stéréotypées tend à les écarter. La disposition des types de personnalité les moins autonomes, donc les plus autoritaires, que pareille production industrielle de la culture parvient à manipuler le plus facilement sur le plan socio-psychologique, et la forme stéréotypée des émissions entrent ici en résonance, ou parfois en corrélation. La stéréotypie qui apaise les personnalités les plus incertaines est nourrie par la stéréotypie des émissions. Le type de personnalités plus autonomes peut choisir de ne pas regarder ce genre de programme, ou alors de s'en amuser avec une distance ironique, sinon analytique. 
Les études sur la personnalité parle de différents caractères, contestataire, bohémien ou libertaire, autonome, liberal en anglais, sachant que l'ensemble des ces attitudes sociales ne composent qu'une minorité des enquêtées. Les deux aspects de l'analyse, la socialisation des personnalités et les traits caractéristiques des programmes médiatiques, sont ensuite discutés dans un même mouvement par Adorno dans ses études sur la personnalité et le préjugé. Dans les cours adornien des années 1960, publiés à titre posthume, se trouvent des séances entières consacrées à la typologie sociale (qui s'oppose à la psychologie individuelle), à la méthode et aux enjeux des théories de Karl Marx et Max Weber. ${ }^{40}$

Dans ses études sur la télévision et les schémas de la culture de masse, Adorno noue le lien entre l'analyse socio-psychologique de divers types de personnalité qui se regroupent par le biais de l'identification, et l'analyse structurale des émissions de télévision. ${ }^{41} \mathrm{Il}$ transpose la méthode des études sur la personnalité "pour étudier les effets potentiels de la télévision", cela à l'aide de catégories qui émanent de "la psychologie des profondeurs, et grâce à des connaissances préalables sur les mass médias." Dans ce dessein, il scrute les multiples couches de signification qui se superposent dans les mass médias, qui comportent des messages manifestes et des messages cachés. Si le message des émissions est souvent anti-totalitaire, leur symbolique ne reproduit pas moins la crédulité et la passivité intellectuelle. Un exemple du sens caché qu'Adorno expose est un téléfilm qui met en scène une jeune institutrice en galère, maltraitée et sous-payée, figure qui construit un compromis "entre le mépris dominant pour les intellectuels et un respect tout autant conventionnel pour la culture" ${ }^{42}$ Les traits charmants, rigolos et vivants de l'héroïne, qui permettent aux spectateurs/spectatrices de s'identifier à elle, viennent immédiatement compenser sa condition sociale subalterne, pénible. Le message implicite est : vous pouvez supporter votre frustration si vous la prenez avec un peu d'humour.

Aujourd'hui, le message implicite ou subconscient que l'industrie de la culture produit peut parfois se passer de tout scénario affirmé, dans les téléréalités qui semblent filmer une vie quotidienne en temps réel, alors qu'en réalité ces productions reposent à chaque fois sur une scénarisation écrite et règlementée, le téléacteur Trump illustre le fake de cette représentation, et les survivants de ce genre d'exercice en témoignent. ${ }^{43}$ Le même schéma caractérise les émissions de chant du radio-crochet des années 1950 et de télécrochet à l'heure actuelles, qui semblent chercher la nouvelle star. ${ }^{44}$

Dans leur chapitre sur l'industrie de la culture, le deux auteurs de La dialectique de la raison écrivent que ce dispositif, tout en se présentant dans son raffinement le plus riche, pousse les outsiders à la faillite ou à l'action collective..$^{45}$ Adorno ne dit pas du tout qu'il ne faut pas regarder la télévision, il plaide au contraire pour une éducation critique du public, face au constat que la plupart des émissions participent à l'appauvrissement culturel. ${ }^{46}$

Un disciple d'Habermas a cru relativiser cette approche critique, en soulevant l'anecdote selon laquelle Theodor et Gretel Adorno auraient aimé regarder la série télé hebdomadaire Daktari (CBS, 1966-69), qui joue dans un refuge animalier africain, filmé en réalité dans le zoo de Los Angeles, feuilleton dont les véritables héros sont une guenon impertinente et un lion qui louche ${ }^{47}$. La lecture habermassienne de cette anecdote sousentend que la critique médiatique de Horkheimer et Adorno est intenable, puisque les Adorno regardent eux-mêmes la télévision. A mon sens, le choix de cette série, dont les personnages sont plutôt décalés au vu des standards californiens qu'Adorno a analysé dans ses études, expriment plutôt sa tendresse pour des figures qui sauvent une part d'humanité sous des aspects animaliers, à la manière des fables d'Aesop. La guenon 
impertinente et le lion qui louche invoquent un imaginaire enfantin qu'Adorno aborde dans ses écrits les plus élaborés sous la forme de la subjectivité rebelle qui résiste à la totalisation sociale. La dialectique de la raison encourage la compréhension des outsiders, que le capitalisme a marginalisé et marque au fer rouge comme étant des inadaptés. Bien entendu, le modèle critique peut s'appliquer à Daktari, tout comme il peut être déployé à partir d'un seul livre pour enfants, Le Struwwelpeter, comme Lucia Sagradini l'a montré, livre qui figure dans la collection de Benjamin et dont Adorno reprend le titre pour ouvrir un chapitre dans les Minima moralia. ${ }^{48}$

\section{Extensions. Francfort, Paris, Hanovre (1951-1987)}

51 De retour en Europe, l'approche critique des feuilletons télé et autres produits des mass médias que propose Adorno va permettre la rencontre avec l'équipe de chercheurs du CNRS qui sont à l'origine de la revue Communications dans les années 60 , et elle va inspirer les écrits de Negt et Kluge sur l'audiovisuel allemand au début des années 1970.

Dans la discussion française, ces prolongations disparaissent généralement du tableau, ce qui apparait aussi dans le fait que le chapitre sur l'industrie de la culture de 1944 se trouve cité indépendamment de la complétion qu'Adorno apporte de son vivant, en 1963 par son post-scriptum qui circule en français sous le titre L'industrie culturelle, et qu'il élargit surtout par un texte plus important de 1969 qui comprend 37 pages : Das Schema der Massenkultur (Le schéma de la culture de masse) dont il n'existe aucune traduction française. ${ }^{49}$ Le texte, publié en ajout à la nouvelle édition de La dialectique de la raison en 1969, a pour sous-titre "L'industrie de la culture, suite".

Sur la base du clair constat des ressorts de l'industrie de la culture et des mass médias, Adorno n'oublie jamais de souligner la possibilité d'une émancipation des sujets, perspective qu'il partage avec Benjamin, avec Gretel Adorno et avec les autres chercheuses et chercheurs de la Théorie critique. La possibilité de "l'émancipation du sujet" qu'il nomme dans La dialectique négative, se manifeste concrètement dans l'attitude sociale qu'incarne la personnalité autonome, sur le plan socio-psychologique et sociologique où se situent les études sur la personnalité autoritaire. Dans le même temps, le théoricien critique signale les résistances pratiques au capitalisme tardif, en introduction au congrès de sociologie de 1968. En termes esthétiques, l'émancipation du sujet peut se réaliser dans l'expérience sensible, non-règlementée, à travers laquelle les individus et collectifs peuvent se réapproprier le monde et l'art, à condition d'aller à l'encontre des fausses représentations du capitalisme et de son monde administré.

Dans ses écrits au sujet d'une éducation démocratique pour l'usage des médias, Adorno aborde la faisabilité et quelques exemples de programmes alternatifs, ce qui ne contredit en rien les analyses critiques. Il distingue la possibilité de diffuser des contenus propres à stimuler la formation culturelle de la personnalité, et la fonction standard de la télé qui est celle d'une régression en masse. ${ }^{50}$ Dans La dialectique négative, Adorno aborde aussi la question de l'émancipation du sujet:

Les complaintes à propos d'une perte de la mise en forme augmentent au fur et à mesure que celle-ci gagne en puissance. Les institutions ont gagné un pouvoir encore jamais atteint; déjà elles s'affirment dans un genre de style de l'industrie de la culture qui s'expose à la lumière des néons, irradiant le monde comme le fit jadis le baroque. Le conflit entre la subjectivité et les formes, qui ne souffre plus d'aucune modération, se retourne en une identification avec l'agresseur, sous la 
domination sans partage d'une conscience qui fait sans cesse l'expérience de sa propre impuissance, une conscience qui manque de cette confiance qui la rendrait capable de changer l'Institution et ses traits spirituels. ${ }^{51}$

Dans les conditions imposées par l'industrie de la culture, le principe Trump s'affiche encore comme statut quo, alors que les victimes de cette agression s'identifient à l'agresseur, mais la critique de l'Institution rend bien entendu pensable un renversement révolutionnaire de la situation : l'émancipation du sujet. Die Emanzipation des Subjekts, qu'Adorno évoque deux ans avant Mai 68.

Dans la "suite" à l'industrie de la culture qu'Adorno écrit en 1969 pour compléter le modèle original, il prolonge cette réflexion à travers sa critique d'Heidegger, qui dénonce la curiosité comme un élément de la déchéance de l'existence. Adorno conçoit bien la possibilité régressive d'une curiosité qui alimente la presse people, une curiosité qui sert de ciment à la production culturelle de masse et de son armée de réserve d'individus désorientés, mais il refuse catégoriquement l'idée heidéggerienne selon laquelle cette curiosité serait un trait essentiel de l'existence humaine. En proclamant, dans Etre et temps, que pareille curiosité serait l'essence de l'humanité, le penseur de la forte noire fait retomber la faute de cette situation sur les victimes, au lieu de désigner les agresseurs. ${ }^{52} \mathrm{~A}$ cet endroit précis se situe le clivage irréductible qui sépare le pessimisme culturel des nazis de la lucidité émancipatrice des théoriciens critiques.

La perspective de l'émancipation du sujet part du concept d'Eigensinn (subjectivité rebelle), dont Adorno souligne la pertinence dans la Dialectique négative, face aux représentations capitalistes, administratives et médiatiques établies. Ce versant de la subjectivité rebelle qui traverse peu ou prou tous les êtres humains, malgré la totalisation sociale et historique qu'ils subissent, va guider le grand livre de Negt et Kluge Histoire et subjectivité rebelle. La traduction d'Eigensinn par subjectivité rebelle correspond à une solution conceptuelle que nous avons introduit avec l'accord d'Oskar Negt, de Miguel Abensour et de Jean-Marie Vincent. ${ }^{53} \mathrm{Si}$ la cohérence et la récurrence de concepts adorniens Eigensinn, Stereotypie, Kulturindustrie - disparait dans les traductions françaises qui proposent diverses reformulations des mêmes concepts jusqu'au choix des titres, elle n'en demeure pas moins explicite dans les textes originaux.

Comme toujours, la recherche sociale de la Théorie critique vient saisir par des enquêtes empiriques la pertinence des distinctions conceptuelles et la faculté de juger issue du travail philosophique. A Francfort, Pollock, Adorno et alli organisent une novelle enquête dans le contexte post fasciste de l'Allemagne de l'Ouest, à partir de 1957, intitulée Gruppenexperiment, une expérimentation collective donc..$^{54}$ Le projet analyse plusieurs groupes de travailleurs allemands pour saisir leurs potentialités démocratiques après la défaite d'Hitler. La recherche veut saisir les motivations socio-psychologiques des sujets et leurs différents schèmes d'interprétation (plus ou moins démocratiques) à partir de leur situation sociale, à la suite des études sur la personnalité autoritaire. Au centre de l'attention sociologique se trouve alors le "potentiel de résistance » démocratique des acteurs, qui peut se faire jour dans le décalage, entre opinions stéréotypées et personnalités plus ou moins autonomes.

Dans La dialectique négative, Adorno conceptualise ces connaissances, en recourant au concept critique d'industrie de la culture, dans le but de dépasser une posture philosophique traditionnelle, auto-référentielle, qui en reste à la discussion abstraite de la logique ou du devenir de l'être. Une véritable ontologie de la culture "devrait saisir en quoi la culture a échoué", écrit-il, pourquoi elle a pu échouer parmi les masses, au profit 
d'une culture de masse qui se retourne contre les masses, au détriment de l'émancipation du sujet? La seule position théorique légitime d'une telle ontologie serait la compréhension du devenir identitaire de l'être qui se manifeste dans la construction de la Kulturindustrie..$^{55}$ La quête du bien ne saurait se placer à l'intérieur du cadre ontologique, mais ce qui importe est tout "ce qui échappe à l'ontologie". La dialectique négative soutient la résistance des sujets à la totalisation régressive et à une philosophie qui voudrait s'ériger par dessus leurs têtes. Ce qui lui importe est de "faire valser" les rapports sociaux et leur fausse représentation. Adorno ne se dit pas "philosophe", d'une manière isolée, mais souligne que la Théorie critique pense la dialectique de l'expérience et du sujet.

\section{Sens caché (Paris)}

60 L'ensemble des ces connaissances et approches critiques vont être au centre des interventions parisiennes d'Adorno, qui répond notamment à une invitation de George Friedmann pour le CNRS en 1958, et à Cerisy la même année sur une recommandation de Lucien Goldmann, suivi d'une intervention adornienne au Collège de France en $1961^{56}$. Les discussions parisiennes autour d'Adorno coïncident ainsi avec le lancement de la revue Communications, en 1961, par des chercheurs comme Friedmann et Morin, qui cherchent à tourner la sociologie vers la compréhension des médias de masse. Dans le numéro 1, Friedmann signe un article au sujet de la "culture de masse", tandis que Morin examine "l'industrie culturelle", juste avant que paraisse un article d'Adorno, dont le titre est traduit par "L'industrie culturelle". ${ }^{57}$ L'article de Morin de 1961 confine à la confusion; il y propose de parler de "culture industrielle" à la place "d'industrie culturelle", et il y définit "l'homme moyen" comme une sorte de médiocrité humaine. Herbert Marcuse avait auparavant utilisé ce concept pour montrer les limites de l'illusion statistique, qui décrit une personne moyenne abstraite qui ne correspond à aucun individu en particulier ${ }^{58}$ Le grand mérite de Morin reste d'avoir vulgarisé assez tôt l'idée d'une marchandisation en masse de la culture, y compris de la culture populaire. Le sociologue français a indiqué, plus tard, son rapport à La dialectique de la raison de Horkheimer et Adorno, qui semble d'un genre relâchés ${ }^{5}$.

Dans l'ensemble, la réception parisienne manque un peu de cohérence et n'assure pas la continuité des concepts. Le En France, le même concept adornien Kulturindustrie se retrouve sous l'appellation "production de biens culturels", "industrie culturelle", "industries culturelles", voir "culture industrielle", "industries de la culture et de la communication", etc. La transmission est précaire, le concept devient illisible.

Il serait néanmoins possible de scruter l'influence des recherches sociales associés à Adorno, qui sont alors arrivées à un point culminant, sur des auteurs français dont Pierre Bourdieu fait partie. Il nous avait indiqué de son vivant qu'il lisait les sociologues et théoriciens allemands directement dans le texte, ce qui apparait noir sur blanc dans sa discussion de la philosophie politique de Martin Heidegger, où Bourdieu cite les écrits d'Adorno en allemand.$^{60}$ Les emprunts bourdieusiens à la théorie sociale de l'habitus de Norbert Elias sont bien connu, et l'analyse des standards culturels de masse selon divers publics qui est exposée dans La Distinction rappelle certaines approches de la recherche sociale francfortoise antérieure, dont la typologie sociale des études sur la personnalité autoritaire et l'analyse structurale des biens culturels par Karacauer, de même que la critique de la télévision comme organe de reproduction sociale en masse résonne avec les 
études adorniennes des années $1950 .{ }^{61}$ Ce qui sépare Bourdieu de la recherche sociale francfortoise est le postulat catégorique, qu'il affirme avec Passeron : la mort définitive du sujet sous les conditions de la reproduction, affirmation qui conduit ensuite à l'idée que les groupes subalternes, dont les ouvriers, ne peuvent en aucun cas agir par euxmêmes ou se départir de quelque façon que ce soit la culture bourgeoise dominante. ${ }^{62}$ C'est un cadre théorique qui, dans sa forme académique pure, laisse peu de place à l'émancipation du sujet, qui anime Adorno à la suite de Marx. En réalité, Bourdieu a assoupli cette conception au contact de l'espace public oppositionnel qui s'est manifesté lors des grèves de l'hiver 1995, avant de reformuler sa perspective dans un texte sur les perspectives de la protestation, né de l'échange avec des chercheurs allemands. ${ }^{63} \mathrm{Il}$ indique l'affaiblissement de la coupure culturelle entre étudiants, travailleurs manuels ou fils d'ouvriers éduqués, tous touchés par la crise économique. Cette inflexion ne l'incite pas à revenir sur la Théorie critique, contrairement à Foucault qui n'a pas hésité à rendre hommage à Horkheimer et Adorno. Actuellement, le débat sur les réappropriations réciproques des sociologies de Bourdieu et d'Adorno a lieu en Allemagne, il n'existe pas encore en France. ${ }^{64}$

\section{Sens unique (Starnberg)}

63 Un autre élément qui perturbe la transmission cohérente et intelligible du concept d'industrie de la culture en tant que modèle critique est l'héritage disputé de la pensée adornienne, en tant que fil rouge de la Théorie critique. Après la mort d'Adorno, en 1969, Gerhard Brandt prend sa succession en tant que directeur de l'institut francfortois, mais il se donne la mort en 1987, ce qui interrompt brutalement la transmission intellectuelle et personnelle dans un contexte intellectuel et idéologique néoconservateur, très défavorable, marqué par le recul de toutes les approches critiques. Un livre récent dresse par exemple les actions à travers lesquelles l'héritage adornien a été écarté des facultés de sciences de la communication, par des coalitions conservatrices. ${ }^{65}$

Dans le même temps, Jürgen Habermas propose sa Théorie de l'agir communicationnel afin de remplacer la Théorie critique et sa conception de la recherche sociale, en premier lieu par le recours à la sociologie traditionnelle d'Emile Durkheim, ce qu'il expose dans une partie d'une soixantaine de pages, intitulée 'Critique de la raison instrumentale'. ${ }^{66} \mathrm{Il}$ y contredit l'ensemble des conceptions de Horkheimer et Adorno, en s'appuyant au passage sur Axel Honneth, qui va en prolonger les arguments jusqu'à aujourd'hui. Horkheimer, Adorno et leurs héritiers contemporains, d'une part, Jürgen Habermas et ses disciples d'autre part, ces deux courants poursuivent des projets de recherche fondamentalement différents, ce que de nombreuses publications ont mis en relief. ${ }^{67}$ Dans La théorie de l'agir communicationnel Habermas évacue méthodiquement, les concepts critiques de Marx d'abord, de toute l'approche de La dialectique de la raison ensuite, et enfin l'ensemble des études critiques au sujet des mass médias. Cela culmine dans son idée que :

la question de savoir si "une culture de masse conçue pour des médias de masse va actionner des forces qui favorisent une intégration régressive de la conscience (...) ne dépend en rien du fait que les lois du marché pénètrent la production culturelle.

68

65 En réalité, la loi du marché ne pénètre pas seulement la culture, mais elle est entièrement régie par l'industrie de la culture, sur la base d'un rapport social défini par la primauté du capitalisme. En écartant ce constat de base, Habermas ne fait que confirmer la critique que Horkheimer et Adorno partagent dans leur correspondance à son égard, où 
Horkheimer craint déjà, en 1957, que la lecture habermassienne de Marx puisse préparer des conceptualisations hâtives et acritiques, ce que l'intéressé a d'ailleurs confirmé dans son ouvrage Après Marx. ${ }^{69}$ Horkheimer remarque encore avec un brin d'ironie que le "cas" Habermas montre qu'il est possible de travailler dans l'Institut francfortois :

sans jamais faire des expériences susceptibles d'étendre sa propre connaissance de

la réalité sociale, hélas, sans même employer sa raison pour méditer le présent. ${ }^{70}$

Cela fait qu'Habermas est invité à préparer son habilitation à diriger des recherches ailleurs, à Marburg, à la fin des années 1950 déjà. En devenant co-directeur de l'Institut Max Planck, en 1971, sous la direction de Richard von Weizsäcker, Habermas sort explicitement de la Théorie critique, un moment qu'il définit lui-même comme un geste symbolique qui "met fin à l'Ecole de Francfort". ${ }^{71}$ Son nouveau directeur, Weizsäcker, est un homme de droite bien connu. ${ }^{72}$ Le projet de collaboration scientifique échoue assez rapidement, mais la rupture avec la Théorie critique s'approfondit encore. Dans sa Théorie de l'agir communicationnel, Habermas ne mentionne d'ailleurs aucune des enquêtes empiriques de la Théorie critique. Il se contente de commentaires philosophiques sceptiques sur La dialectique de la raison. ${ }^{73}$ Aujourd'hui, le philosophe Habermas veut donner raison à Horkheimer qui a interrogé son manque de distance critique, puisque le premier a choisi de rallier sans ambages le pouvoir "fascinant" et "éblouissant" de la présidence Macron $^{74}$. S'éblouir du pouvoir politique et médiatique est une attitude incompatible avec le programme de recherche de la Théorie critique, aux yeux de Horkheimer et Adorno.

\section{Sens critique (Hanovre)}

Dès le début des années 1970, Oskar Negt et Alexander Kluge apportent la preuve que la Théorie critique perdure, persiste et signe, au delà de la mort des fondateurs, et à côté de l'institut francfortois, lorsque Negt prend la direction de l'institut de sciences sociales de l'Université d'Hanovre. Les deux auteurs, formés par Adorno, livrent alors la première analyse de l'audiovisuel public ouest-allemand, qu'ils qualifient de "grande entreprise de l'industrie de la culture". ${ }^{75}$ Ils constatent le décalage qui existe entre la normativité de la raison issue de la Aufklärung, et une pratique très éloignée des idéaux bourgeois. Leurs recherches formulent la critique des médias à l'ère "post-bourgeoise" de la société de masse. Ils remarquent tout à fait que la République fédérale ne laisse pas libre cours au marche, aux jeux de correspondance entre la publicité entrepreneuriale et l'offre médiatique, mais qu'elle a adopté une forte législation concernent la télévision publique. Elle fut instaurée en réaction à l'usage que l'Etat nazi avait fait des médias de masse. La décision politique post-fasciste, et pour ainsi dire post-bourgeoise, a donc pour effet paradoxal de rétablir une programmation télévisuelle qui n'est pas immédiatement marchande, mais semble rétablir des normes générales qui rappellent le schème républicain de l'intérêt général et donc la publicité bourgeoise originaire, dans toute son ambiguïté. De la même manière que le sujet est réputé libre selon la déclaration des droits de l'homme, le spectateur de la télévision publique doit être considéré comme un sujet autonome, ce qui fait que la programmation culturelle est supposée stimuler l'autonomie des spectateurs, sans pour autant nourrir une aspiration au bonheur qui menacerait l'équilibre social. La télévision publique ne peut pas faire appel aux souhaits particuliers des sujets qui voudraient changer leur vie, mais doit diffuser ses programmes parfois bien intentionnés en direction d'un public standard, qui repose sur une moyenne sociale, un "homme moyen" (Herbert Marcuse) qui ne correspond à personne en particulier. Dès les 
années 1970, Negt et Kluge ont averti que les citoyens et spectateurs de l'audio-visuel public n'allaient pas se mobiliser, sur cette base, pour défendre ce secteur face aux assauts prévisibles des productions privées, ce qui s'est vérifié en France, en Italie et an Allemagne au moment des libéralisations des années 1980 et 90 . Pendant ce temps, le secteur public se maintient de manière assez forte en Allemagne, mais malgré la participation des partis de gauche au conseil d'administration et de surveillance, et malgré l'intervention institutionnelle des syndicats, le mécanisme d'abstraction et de standardisation produit des effets réalistes, conformistes et conservateurs. L'exemple de la première chaine allemande (ARD) sert à illustrer ce processus dans le cadre du modèle fédéral. Les différents Etats ou régions (Länder), sous l'égide de leurs gouvernements politiques respectifs, produisent leurs propres programmes sous le même toit, la ARD, qui garantit un tronc commun et un cadre pluraliste. La recherche de compromis joue à plein en faveur de positions consensuelles, souvent conformistes ou conservatrices, tandis que la gestion quantitative des plannings et programmes, en phase avec les intérêts de rendement à long terme, rend difficile des changements qualitatifs.

Des enquêtes récentes, réalisées après l'an 2000, montrent par exemple que la forme et le contenu des JT des chaines privés et publiques allemandes tendent à se ressembler. Il serait possible de montrer le même phénomène en France et ailleurs.

Le livre Histoire et subjectitivité rebelle de Negt et Kluge qui prolonge l'esprit de la dialectique négativetrouve son point de chute, en 1980, dans un chapitre qui reprend directement l'inspiration marxienne première de La dialectique de la raison, il est intitulé : Valeur d'échange, caractère fétiche de la marchandise, iconoclasme. ${ }^{76}$ L'iconoclasme vise la destruction de l'image pieuse et la fausse représentation de l'industrie de la culture, par le recours direct à la Dialectique de la raison. Ce leitmotiv a guidé les travaux de l'institut en sciences sociales de l'Université d'Hanovre sous la direction de Negt, jusqu'en 2003 et audelà.

\section{Mondialisation capitaliste, flux global, subjectivité rebelle (1989-2018)}

Dans le cadre global d'une analyse critique de l'industrie de la culture, Kracauer et Benjamin ont analysé le cinéma et le film en noir et blanc, Adorno la radio et la télévision américaine, Negt et Kluge l'audiovisuel public de l'après guerre. Jameson s'inscrit dans cette même filiation adornienne pour commenter les chaines de télé couleur en continu, dont le premier exemple est MTV (Music television), crée en 1984 à New York City. ${ }^{77}$ Jameson remarque que ce type de chaine nouvelle qui diffuse des clips en continu, bientôt rejointe par d'autres chaines qui diffusent l'info du jour sans interruption, crée un flux visuel constant qui ne connait ni pause, ni relâche, ni répit. La télévision traditionnelle annonçait encore des programmes distincts, parfois aidé des speakers et speakerines qui guidaient le spectateur, et l'émission s'arrêtait la nuit. Désormais, seul les entrefilets publicitaires rythment encore un tant soit peu le déversement d'images. Ce nouveau flux, qui disperse l'attention et qui ne tolère pas le sentiment d'ennui, rend difficile la distanciation critique. Jameson se rappelle d'un colloque où la plupart des participants n'ont rien à dire sur l'expansion de la télévision, sauf à rappeler le concept de "flux total" de Raymond Williams. Il commente cela : "le blocage de toute pense originale, devant cette 
compacte petite fenêtre, contre laquelle nous nous cognons la tête, n'est pas sans rapport, précisément, avec le flux total ou global que nous observons à travers elle." 78

Ses considérations se poursuivent alors dans une exploration de la vidéo expérimentale, mais nous prolongeons plutôt l'idée du flux global, en prolongement de l'industrie de la culture. Aujourd'hui, la mondialisation capitaliste permet des échanges sans frontières, appuyés sur un marché dérégulé, la transmission satellitaire, la numérisation des contenus, activités et supports, qui passent aussi par le web. Non seulement, les images peuvent se passer de tout commentaire et défilent sans cesse, mais leur numérisation et mise en réseau fait converger les supports médiatiques, au sein d'une forme multimédiatique, globale et planétaire. Même si chaque média perdure séparément, à la manière du livre, la télévision, le cinéma et la radio sont désormais transmis en continu sous la forme du streaming numérique, qui s'affiche sur toute sorte d'ordinateur portable ou smartphone, dans une interconnexion avec des plateformes vidéos comme Youtube et les réseaux sociaux privés comme Facebook. L'interaction se pratique en temps réel, avec la rapidité d'un SMS ou d'un tweet, dont la capacité d'auto-réflexion et le potentiel critique peut tendre vers zéro. Ce type d'interconnexion et sa mentalité fut nommé la connexion aveuglante par Horkheimer et Adorno (Verblendungszusammenhang). Aux Etats Unis, Adorno avait choisi le courrier des lecteurs des chaines de radio comme support, car le gout formaté et l'opinion dans sa forme conventionnelle s'y expriment d'une manière caractéristique, alors qu'il constatait la simplification des récits au vu du format de téléfilms qui n'excèdent pas une demi heure. Aujourd'hui, les commentaires sur Twitter en trois lignes se passent même de ce temps de recul qu'implique la rédaction d'une lettre postale, alors que l'envoi instantané de vidéos par les réseaux sociaux peut concerner des films qui n'excèdent pas une minute. Cette pratique peu réflexive, sinon régressive, est parfaitement résumée par le président Donald Trump en octobre 2017 :

Tweeter c'est comme une machine à écrire en direct. Dès que je sors le message, vous le relayez immédiatement dans vos émissions télé... Donc si quelqu'un dit quelque chose sur moi, je peux m'en occuper 'bing, bing, bing'. ${ }^{9}$

En marge de colloques universitaires, certains collègues me confient l'impression que les nouvelles possibilités médiatiques en flux leur évoquent. Une chercheuse féministe a évoqué comment les messages simplistes sur Twitter favorisent la répétition de clichés et de préjugés, ce qui la pousse alors à ce commentaire : Twitter est la lie de l'humanité. Un collègue, adepte de Facebook, me disait que pour lui, c'est comme la vielle télé en couleur, mais interactive. Des argumentations académiques plus élaborées, qui reprennent le concept d'industrie de la culture, viennent de rappeler que ces médias en streaming, qui véhiculent le mainstream, devraient de nouveau être appelé pour ce qu'elles sont : des médias de masse ${ }^{80}$ Ils regroupent la somme d'une masse d'individus isolés et dispersés, dont les données privées sont exploitées par les grandes entreprises qui les utilisent à des fins commerciales. Les algorithmes qui gèrent et trient la masse de données disponibles servent à la fois à orienter les individus, à attirer son regard sur des contenus qui peuvent lui ressembler, et à lui proposer des objets de consommation similaires. L'industrie de la culture écrase tout par le principe de similarité, avaient constaté Horkheimer et Adorno. Dans le cas de Facebook, réseau construit sur la représentation fétichiste de soi qui émane des trombinoscope des grands campus et leurs clubs fermés, la fabrication de stéréotypes va jusqu'à la vente de données qui ont alimenté la stratégie médiatique et électorale du candidat Trump, roi de la fausse représentation. Facebook ne vend pas seulement toutes les données privées de ses clients à des entreprises pour favoriser leur marketing publicitaire, mais le réseau social a aussi vendu les données privées de 87 millions de ses 
clients à la société Cambridge Analytica qui en a tiré des profils typiques pour mieux cibler la publicité politique de Trump, en fonction des différents publics qui utilisent les réseaux sociaux. Il ne s'agit pas d'un scandale, comme semble le croire la majeure partie de la presse mondiale, mais d'une claire exposition du fonctionnement routinier de ce mass média.

Les citoyens ne peuvent trouvent un espace de socialisation démocratique à travers ce genre de médias qu'à la seule condition d'aller à l'encontre de leur fonctionnement économique et psychologique préfabriqué, afin de les détourner de leur objectif capitaliste premier, dans le sens d'un débordement pratique.

Ainsi, Bertold Brecht, ami de Benjamin, avait déjà imaginé une démocratisation de la radio à partir des auditeurs qui deviendraient acteurs, idée que Benjamin envisage dans sa potentialité pour le cinéma, avant qu'Adorno n'esquisse les contours d'une pratique émancipatrice de la télévision dans les années 1950. Dans cet esprit, Jameson a discuté la vidéo expérimentale, que Kluge ou Rosler ont pratiqué, sous la forme artistique ou par le film documentaire indépendant, alors que Negt a développé un apprentissage par l'exemple qui permet aux subalternes de se libérer eux-mêmes des représentations schématiques. Il est bien entendu à tout moment possible que les traces de travail vivant et créatif, sans lesquelles l'industrie de la culture ne peut pas fonctionner ni trouver son public, réveillent des souhaits utopiques dans le public qu'elle voudrait divertir. ${ }^{81}$

Aussi, les exemples qui montrent la faculté des sujets à détourner les mass médias capitalistes sont très nombreux. Franz Fanon décrit comment la guerre coloniale en Algérie transforme l'usage de la radio, à l'origine perçu comme un attribut bourgeois des colons importé de la Capitale, mais qui devient un moyen de résistance lorsque les habitants des villages se regroupent pour tenter de capter la fréquence du FLN, ce qui donne lieu à des prises de paroles ad hoc et des discussions collective de décryptage, qui favorisent l'apparition d'un espace public oppositionnel..$^{82} S^{\prime}$ il est vrai que les réseaux sociaux n'ont pas déclenché le 'printemps arabe', comme cela est parfois suggéré abusivement par la presse, le recours à des réseaux de communication à statut privé comme Facebook a néanmoins facilité la coordination des manifestants et des grévistes au cours de la révolution tunisienne de 2010, lorsque les médias traditionnels et les sites Internet oppositionnels étaient censurés ou bloqués par l'Etat. ${ }^{83}$

De même, la télévision américaine avait diffusé des reportages pendant la guerre du Vietnam, du point de vue du belligérant américain, qui ne provoquèrent pas moins un mouvement auto-organisé contre cette guerre, porté à 'intérieur des Etats Unis par des étudiants qui ne sont pas obligés d'aller au front, avec le soutien actif d'Herbert Marcuse. 84

Aujourd'hui, le flux global de Youtube est utilisé par des chaines de télévision alternatives et oppositionnelles de tous les pays, par exemple aux Etats Unis par TYT (Television Young Turks, RealNews, The Humanist Report), des chaines Youtube féministes, socialistes et bien d'autres encore qui défont les stéréotypes et la politique de l'identité. Pendant le mouvement de grève à l'encontre de la "loi travail" de l'été 2016, le blog On vaut mieux que ça a diffusé des vidéos via Youtube, produits par les salariés eux-mêmes, qui y relatent leur expérience du travail et leurs capacités de résistance.

La première mobilisation antifasciste de l'histoire qui s'est appuyée sur des échanges par téléphone portable s'est manifestée dans les rues de Vienne, en 2001, lorsque la jeunesse scolarisée et étudiante s'est concertée à travers ce moyen en apparence individuel, afin de 
manifester contre la participation de l'extrême droite au gouvernement autrichien, imitée par la jeunesse de France en mai 2002. Dans les années 2000, la création d'un blog anonyme pour les ingénieurs et programmateurs du siège européen d'IBM, à Düsseldorf, a permis le déploiement d'une prise de parole contre les abus du management flexible qui incite à l'auto-contrôle, favorisant la discussion transversale, des ateliers d'écriture autour des pressions psychiques subies, et finalement la création d'un syndicat oppositionnel qui est devenu majoritaire aux élections professionnelles..$^{85}$

Il est vrai que la numérisation, qui transforme tout en nombres et chiffres, repose à la base sur un principe binaire tout autant que sur l'abstraction. Hier, ce principe avait permis à l'entreprise IBM de ficher rationnellement des individus, à travers la carte perforée Hollerith, principe appliquée pour l'extermination des victimes du nazisme dans les camps de la mort. Aujourd'hui, le principe numérique permet de contrôler les échanges privés des citoyens. ${ }^{86}$ Ces constats rendent la distanciation adornienne envers le principe d'abstraction et sa standardisation particulièrement intéressante. Cependant, la numérisation dépend, comme tout processus médiatique, du travail vivant des sujets, malgré l'emprise du capital qui la caractérise, ce qui rend possible des débordements et retournements de toute sorte. Le piratage, la réappropriation des logiciels et possibilités numériques par le hacking et l'actualisation de la pratique du bricolage, popularisée sous la forme du do it yourself depuis le mouvement punk, nourrissent ces mouvements qui favorisent une distanciation critique envers l'industrie de la culture, en France et dans le monde.

Manifestement, "les effets de convergence dus à la numérisation du signe font, aujourd'hui, jouer à Internet un rôle central, puisque l'informatique connectée permet de coupler plusieurs formes de production (...), de les coupler aisément à de débats de commentaire, de débat et de socialisation conduisant potentiellement à l'édification d"espaces publics oppositionnels' (Negt)." 87

Nancy Fraser a développé une théorie critique des besoins sociaux, qui part des sujets eux-mêmes, permettant de mettre à distance les définitions imposées par le haut, par l'institution et la représentation, que produit l'espace public et médiatique dominant. L'autrice ne cache pas ses lectures de la Théorie critique (Marcuse et Negt en particulier) qui lui servent de ressource dans une perspective socialiste, post-bourgeoise, qui ne se laisse pas enfermer dans les choix durkheimiens traditionnels d'Habermas et d'Honneth, dont elle a démontré les limites sociologiques et conceptuels. Une telle théorie critique des besoins se souvient de l'émancipation du sujet, qui part de l'expérience et de la prise de parole, et non pas de l'académisme positiviste et des mass médias :

Certaines façons de parler des besoins sont institutionnalisées dans les arènes de discussion centrales du capitalisme tardif : les parlements, les académies, les cours de justice, les mass médias. D'autres manières de parler des besoins sont ramenés à des dialectes socialement marqués et normalement exclus des arènes centrales de discussion". 88

81899 ouvrières illettrées de Gad auraient-elles moins de chances de se faire entendre que neuf milliardaires qui contrôlent économiquement environ $90 \%$ des mass médias en France? ${ }^{89}$

\section{Ouvertures actuelles}

Les ressorts critiques à l'égard de l'industrie de la culture dans le capitalisme tardif, qui, lui, ne parvient pas à articuler sa propre perspective de développement de manière 
cohérente, furent nommées de manière aussi brève que saisissante par Adorno en 1968, à partir des amorces du présent :

la résistance à l'adaptation, la liberté de désigner des objectifs de manière autonome, la nausée face au monde en tant que tromperie et représentation, le souvenir que le changement reste possible. ${ }^{90}$

Les concepts qui rendent pensable et praticable l'émancipation du sujet se trouvent dans La dialectique négative et la sociologie critique adornienne : l'expérience non-réglementée qui ne se laisse pas absorber par les représentations fétichistes du capitalisme et de sa production de masse, et qui se nomme par son Eigensinn, sa subjectivité rebelle. Elle peut se nourrir de potentiels de résistance que divers types de personnalité manifestent à l'encontre des injonctions identitaires et autoritaires de la société, qui tend à marginaliser toute personne qui ne fonctionne pas selon les normes standardisées, alors que la totalité de cette société se montre dysfonctionnelle et irrationnelle.

La résistance à l'industrie de la culture est une résistance à sa stéréotypie générale qui veut écraser toutes les expériences singulière et particulières.

Stéréotypie de la production de masse, de la voiture au film, qui n'interroge pas l'usage et le sens partagé. Stéréotypie des nouvelles filières qui renouvellent les techniques et supports, mais jamais les formes et la création.

Stéréotypie des modes de socialisation qui encouragent la soumission à l'autorité, dans la famille, l'école et l'entreprise, sous peine de relégation des outsiders.

Stéréotypie des informations, messages et opinions qui sont préfabriquées par les mass médias en direction de publics conçus comme des consommateurs, conçu comme des récepteurs crédules, sinon idiots, qui ne doivent pas agir par eux-mêmes malgré un discours démocratique proclamé. Stéréotypie des formes esthétiques, rigides et conventionnelles, par lesquels s'exprime l'industrie de la culture, afin de parfaire la corrélation entre injonctions et propositions standardisées, dans des téléfilms qui ne font que répéter la frustration quotidienne des spectateurs qui cherchent à y échapper par le divertissement.

Stéréotypie de la récupération des formes nouvelles, déviantes ou contre-culturelles, assommés par le principe de la similarité, et qui en sont tous là du retour au même schéma.

89 Adorno refuse catégoriquement de penser ces manifestations sous la forme d'une sociologie positiviste, dénuée de distance critique envers l'objet. Il se tient aussi à distance des recherches administratives et communicationnelles poursuivies par Lazarsfeld, et se méfie d'une philosophie académique dont la logique conduit à l'enfermement, lorsque son ontologie, laissée à son propre devenir, ne peut produit que de l'horreur. ${ }^{91}$ Nous allons retracer cette tendance chez Heidegger et les théoriciens des médias qui la prolongent à un autre endroit, à partir d'un leitmotiv partagé par Benjamin, Brecht et Adorno : "désintégrer Heidegger" (den Heidegger zertrümmern). ${ }^{92}$

Les Minima moralia se trouvent suspendues dans un paragraphe qui s'intitule Pour terminer

Il importe d'ouvrir des perspectives qui exposent le monde dans son caractère décalé, transfiguré, strié de fissures et de crevasses que la lumières messianique espère révéler un jour. Le seul enjeu de la pensée est de développer de telles perspectives, dépourvues d'arbitraire, de pouvoir et de violence, à travers la seule expérience sensible des objets..$^{93}$ 
91 Ces lignes ne vont pas convaincre les personnes qui aiment s'identifier à la representation telle qu'elle se donne à voir, dans son langage fétichiste, formaliste, positiviste ou identitaire. La dialectique, qui se joue entre l'expérience et le concept, à travers la Théorie critique s'est développée en permanence, a produit des centaines de recherches et d'écrits, dont j'ai cité un grand nombre. Cette dialectique de l'expérience et du concept est éclairée par l'analyse de milliers de documents, d'émissions et de films, elle se nourrit de milliers d'entretiens méthodiques, plus de cinq mille pour les seuls textes classiques cités dans cet article.

Notre texte cherche à exposer ces éléments empiriques et conceptuels dans leur propre cohérence, dans leur dialectique subjective-objective. Pourtant, les personnes qui ne sont pas intéressées par l'émancipation du sujet vont toujours trouver des arguments ou prétextes qui les autorisent à écarter l'industrie de la culture en tant que modèle critique. Ces lignes s'adressent plutôt à l'ensemble des sujets qui ressentent l'énorme malaise qui caractérise le présent d'une société qui voit dans son image actuelle qu'elle n'a pas d'avenir. L'approche initiée par Horkheimer et Adorno nous parle à travers son actualité brûlante. La Théorie critique n'a pas dit son dernier mot.

\section{NOTES}

1. Horkheimer/Adorno, Kulturindustrie als Massenbetrug in : Dialektik der Aufklärung, Querido Verlag, 1947; Adorno, Culture Industry, Routledge, 2010. De même, qui nommerait économie aqueuse le secteur qui s'affaire de la gestion de l'eau (Wasserwirtschaft en allemand)?

2. J. Matthews, "Web, Culture Industry and theoretical frameworks" :

http://www.observatoire-omic.org/pdf/

Web_2.0_cultural_industries_and_theoretical_frameworksy_2_.pdf

Ph. Bouquillon, dir, Creative economy, creative industries. Des notions à traduire, PUV, 2012.

3. F. Martel, Mainstream, Flammarion, 2010, p.93 : "Dans l'expression industries créatives, le mot important est création".

4. W. Benjamin, Sur Mickey Mouse, in : Enfance, Payot, 2017. Les films Disney, sous leur kitsch ou clichés, comportent des charges créatives qui ne reposent pas sur le travail de Walt Disney, qui fut un piètre dessinateur, mais qui sont autant de captations qu'il s'agit de saisir. Nous avons p.ex. commenté la scène du Roi Louie dans Le livre de la Jungle (1968), basée sur une improvisation Jazz de Louis Prima, à l'invitation de Bernard Lubat et Fabien Granjon pour les 39èmes Estejades à Uzeste en 2016.

5. K.Marx, Der Fetischcharakter der Ware und sein Geheimnis in : Das Kapital (1867), pp.85-98.

6. Horkheimer/Adorno, Le laboratoire de la Dialectique de la raison. Discussions, notes et fragments inédits, MSH, 2013.

7. M. Martinet, Culture prolétarienne, Maspéro, 1976 (première édition Librairie du Travail, 1935).

8. Adorno, Marx und die Grundbegriffe der soziologischen Theorie in H.G. Backhaus, Dialektik der Wertform, éd. ça ira, 1997; Adorno, Spätkapitalismus oder Industriegesellschaft? in : Aufsätze, Suhrkamp, 1971, notamment pages 149 et 153; voir la traduction française : Capitalisme tardif ou société industrielle, dans Adorno, Société, Payot, 2012. La lecture francfortoise et non-doctrinaire 
de Marx trouve des correspondances chez Henri Lefebvre, Guy Debord ou Mario Tronti que nous ne pouvons exposer ici.

9. Horkheimer/Adorno, Kulturindustrie, Allia, Paris, 2014.

10. M. Rosler, Culture Class, Sternberg Press, 2013; M.Rosler, Le mode artistique de la Révolution, Variations n.16, 2012 : http://variations.revues.org/206

11. Adorno, Dialectique négative (1966), Payot, 2003.

12. G.Brandt, Arbeit, Technik und gesellschaftliche Entwicklung, Suhrkamp, 1990.

13. Cité d'après Siegfried Detlev, Das radikale Milieu, Deutscher Universitäts Verlag, 2004 (nous traduisons).

14. Paul Lazarsfeld, Marie Jahoda et Hans Zeisel, Les chômeurs de Marienthal, Paris, Éditions de Minuit, 1982.Siegfried Kracauer, Les Employés. Aperçus de l'Allemagne nouvelle (1929), Avinus, 2000.

Erich Fromm, Arbeiter und Angestellte am Vorabend des dritten Reiches, DVA, 1980.

15. R. Zoll, Arbeiterbewusstsein in der Krise, Bund,1981; B.Zeuner et alli, Gewerkschaften und Rechtsextremismus, W. Dampfboot, 2007.

16. S. Kracauer, De Caligari à Hitler (1947), L'Age d'Homme, 1960 (les éditions de poche françaises plus récentes ne comportent pas le tableau de l'analyse structurale, AN).

17. C.L. Strauss, Anthropologie structurale (1958), Pocket, 1996; M. Foucault, Dits et écrits, Vol 4, Gallimard, 1994, p.73.

18. S.Kracauer, Ornements de la masse (1927), La Découverte, 2008.

19. S. Freud, Psychologie de masse et analyse du moi (1921), PUF, 2010; W. Reich, La psychologie de masse du fascisme, (1933), Payot, 1977.

20. E.Fromm, La caractérologie psychanalytique et sa signification pour la psychologie sociale in : La crise de la psychanalyse, Anthropos, 1970.

21. E.Fromm, Arbeiter und Angestellte am Vorabend des Dritten Reichs, EVA, 1980.

22. W.Benjamin, L'oeuvre d'art à l'époque de sa reproductibilté technique (1936), Allia, 2004; Benjamin, Sur le concept d'histoire (1942), Payot, 2013; Benjamin, Paris, Capitale du XIXème siècle (1924-38), Allia, 2003.

23. W.Benjamin, Das Kunstwerk im Zeitalter seiner technischen Reproduzierbarkeit (1936), Reclam, 2011, p.52 : "Das Public ist ein Examinator, doch ein zerstreuter".

24. W.Benjamin, (conclusion), L'oeuvre d'art à l'époque de sa reproductibilité technique, Allia, 2004.

25. Adorno/Benjamin, Correspondance 1928-1940, Gallimard, p.373.

26. Adorno, Lettre à Lazarsfeld du 24/01/1938, au sujet d'un "Memorandum" de recherche commun.

27. S. Cavin, Adorno. Lazarsfeld \& The Princeton Radio Project, 1938-194, American Sociological Association Annual Meeting, 6/2008 (pdf), http://citation.allacademic.com/meta/ p237089_index.html

28. Adorno, The Current of music, Suhrkamp, 2006.

29. Adorno, Memorandum an Dr. Lazarsfeld (geplante Studien), 22/06/1941, voir Adorno Archiv Berlin, TS 51481-87

30. Adorno, Le conflit des sociologies, Payot, 2016.

31. Horkheimer, Adorno, Dialektik der Aufklärung, Suhrkamp, 1997, p.144.

32. Martina Thiele, Medien und Stereotype, Transcript 2015.

33. Adorno (et alli). Etudes sur la personnalité autoritaire, Allia, 2007.

34. Adorno, Studien zum autoritären Charakter, Suhrkamp, 1995, p.24.

35. op.cit., p.37.

36. op.cit., p.81.

37. Adorno/Frenkel-Brunswik/Levinson/Sanford, The Authorian Personality, vol.1-5, The Norton Library, 1950.

38. Adorno, Fernsehen als Ideologie; Prolog zum Fernsehen, in : Eingriffe : neun kritische Modelle, Suhrkamp, 1963. Adorno, Modèles critiques, Payot, 2003. 
39. Adorno, section Vorträge (Funkhaus Wien, mai 1969), Adorno-Archiv Berlin, Akademie der Wissenschaften.

40. Adorno, Philosophie und Soziologie (1960) in : Nachgelassenen Schriften Band 6, Suhrkamp, pp.261-277.

41. Adorno, Television and the patterns of mass culture, Quarterly of film, radio and television, n.8, 1954, pp. 213-35; Adorno, La télévision et les patterns de la culture de masse, Réseaux n.44, 1990.

42. op.cit., p.233.

43. W.E.Wittkoffer, op.cit.; Loana, Elle m'appelait miette, 2001.

44. A titre d'exemple, Kristov Leroy, Dans la secte Nouvelle Star, 2013.

45. Horkheimer/Adorno, Dialektik der Aufklärung, Suhrkamp, 1997, p.156 et 322.

46. Adorno, Fernsehen und Bildung in : Erziehung zur Mündigkeit, Suhrkamp, 1971

47. R.Wiggershaus, Theodor W. Adorno, Beck, 2004. Pour une lecture adornienne, voir D. Claussen, Adorno, Fischer, 2003.

48. L. Sagradini, Walter le dépeigné. Réflexions entrelacées autour de l'album allemand Struwwelpeter et de Walter Benjamin, Revue Streane n.5, BNF/OpenEdition, 2013; Adorno, Struwwelpeter, Minima moralia, Suhrkamp, 1951, p.60.

49. Adorno, Das Schema der Massenkultur, in Dialektik der Aufklärung, Fischer Verlag, 1969; Suhrkamp, 1997, p.299-235. J'ose espérer que le titre de ce texte ne sera pas traduit un jour par Le schéma de la masse culturelle, en corrélation avec l'industrie culturelle.

50. Adorno, Fernsehen und Bildung in : Erziehung zur Mündigkeit, 1971, pp.50-69.

51. Adorno, Negative Dialektik, Suhrkamp, (1966) 1970, nous tradusisons.

52. Adorno, Das Schema der Massenkultur, op.cit., p. 321-22.

53. A. Neumann, Espace public oppositionnel, subjectivité rebelle, travail vivant, préface à 0 . Negt, L'espace public oppositionnel, Payot (Critique de la Politique), 2007, pp. 7-27; A. Neumann, Agir communicationnel ou subjectivité rebelle (Eigensinn) in : Après Habermas, Delga, 2015, pp.129-142.

54. Les contours du projet apparaissent dans la correspondance Adorno/Horkheimer, Band IV, à partir du 25/2/957, Suhrkamp, pp.405-418.Voir aussi Alex Demiroviç, «Gruppenexperiment » in : Der nonkonformistische Intellektuelle, Suhrkamp, 1999, pp.335-372.

55. Adorno, Negative Dialektik (1966), Suhrkamp, 1997, p.128; Adorno, Ontologie und Dialektik (1960), Suhrkamp, 2010.

56. Voir les correspondances d'Adorno de 1958 à 1961, et la conférence d'Adorno en français Etudes sur les préjugés, Paris I-CNRS, 1950 : Adorno Archiv Berlin. Voir aussi : "Dialogue. Th. W. Adorno - L.Goldmann"(1968), Revue de l'institut de sociologie n.3, 1973, pp. 525-542.

57. http://www.persee.fr/issue/comm_0588-8018_1961_num_1_1

58. H.Marcuse, L'homme unidimensionnel (1964), éditions de Minuit, 1968.

59. E. Morin, Pour une anthropolitique, entretien avec W.Graf et A. Neumann in : Variations n.9, Parangon, 2007, http://variations.revues.org/463

60. P. Bourdieu, L'ontologie politique de Martin Heidegger, éd. Minuit, 1975, p.10 et 81.

61. P. Bourdieu, La Distinction, éd. Minuit, 1979; Bourdieu, La télévision, Raisons d'agir, 1996.

62. Bourdieu/Passeron, La reproduction, éd. de Minuit, 1970; Bourdieu, La Distinction, 1979, p.541.

63. Pierre Bourdieu, «Pour un nouvel internationalisme» in : A. Neumann (dir.), Les perspectives de la protestation, Syllepse, 1998, p. 30.

64. U. Bauer et alli, Bourdieu und die Frankfurter Schule. Kritische Gesellschaftstheorie im Zeitalter des Neoliberalismus, Transcript Verlag, 2014.

65. Andreas Scheu, Adornos Erben in der Kommunikationswissenschaft, Halem Verlag, 2012.

66. J.Habermas, Theorie des kommunikativen Handelns, Band 1, Suhrkamp, 1981, pp.455-534. Habermas, La théorie de l'agir communicationnel, Fayard, 1987.

67. A.Demirovic, Der non-konformistische Intellektuelle, Suhrkamp, 1999; W.Lenk, Kritische Theorie und politischer Eingriff, Offizin, 1999; Steinert, Industriekultur als Forschungsprogramm, 
W.Dampfboot, 2007; M. Acikgöz, Die Permanenz der kritischen Theorie, W. Dampfboot, 2014; A.Neumann, Après Habermas, Delga, 2017.

68. J. Habermas, Theorie des kommunikativen Handelns, Band 1, Suhrkamp, 1981, p.497.

69. J. Habermas, Après Marx, Fayard, 1979. L'auteur y affirme que les trois principales répliques philosophiques au scientisme positiviste seraient le relativisme, le marxisme soviétique, et l'ontologie d'Heidegger. La Théorie critique contemporaine, associée aux marxismes critiques sont traités au détour d'un paragraphe de sept lignes (pp.55-56 du texte original, ed Suhrkamp, 1976).

70. Adorno/Horkheimer, Briefwechsel, IV, 1950-69, Suhrkamp, p.508 (nous tradusions). Adorno/ Horkheimer, Correspondance, Klincksieck, à paraître.

71. S. Müller Dohm, Jürgen Habermas. Eine Biographie, Suhrkamp, 2014, p.226.

72. Weizsäcker fut un ancien membre du programme d'armement nucléaire du régime nazi pendant la seconde guerre mondial, fait amplement documenté que l'intéressé a tenté de minimiser. La correspondance du physicien Heisenberg témoigne clairement de son implication directe, en particulier une lettre daté du 14/10/1943, où il apparait que Weizsäcker veut "exterminer" tous ceux qui ne partagent pas son projet : Werner et Elisabeth Heisenberg, Liebe Li, ed. Residenz, 2011.

73. Habermas, op.cit. La seule expérience empirique que Habermas ait jamais pu conceptualiser directement concerne une étude de 1961, sur la politisation estudiantine, encadrée par Friedeburg et Adorno. Adorno/Habermas/Freideburg/Oehler/Weltz, Student und Politik, Luchterhand, 1961.

74. Habermas, "Ce fascinant Monsieur Macron", Obs, 25/10/2017. Seul un journalisme hagiographique comme celui que Nicolas Weill ose exposer dans Le Monde des livres du 23/2/2018 peut prétendre qu'Habermas aurait été "trop à gauche" aux yeux de Horkheimer et Adorno, qui préparent alors un nouveau manifeste communiste : Towards a new manifesto, Verso Books, 2012.

75. Negt/Kluge, Öffentlichkeit und Erfahrung, Suhrkamp, 1971; Negt, L'espace public oppositionnel, 2007; Negt/Kluge et alli, La télévision publique. De la publicité bourgeoise à la technique concrète, Réseaux n.44, 1990, p.243-69.

76. Negt/Kluge, Tauschwert, Fetischcharakter, Bildersturm, in : Geschichte und Eigensinn, Zweitausendeins, 1980, pp. 1030-89.

77. F.Jameson, On Negt and Kluge, October, vol.46, MIT Press, 1988, pp.151-177.

78. F. Jameson, Le postmodernisme ou la logique du capitalisme tardif, Les Beaux arts de Paris éditions, 2012, p.125. Il est possible que cette thèse post-moderniste soit déjà dépassée en faveur d'un post-postmodernisme, au vu du retour des clivages les plus classiques de la modernité : capital-travail, Etat-démocratie, soumission-liberté, mass médias-sujets, science-obscurantisme, art-commerce.

79. http://www.abc.net.au/news/2017-10-22/donald-trump-defends-twitter-tweets-key-towhite-house-victory/9074330

80. D.E. Wittkower, Facebook and philosophy what's on your mind? , Open court - Carus publishing, 2010, p.164

81. O.Negt, L'espace public oppositionnel, Payot, 2007.

82. F. Fanon, Sociologie d'une révolution, Maspero, 1968.

83. G. Achcar, Le peuple veut. Une exploration radicale du printemps arabe, Actes Sud, 2013.

84. H.Marcuse, The Vietnam War, 22/5/1966 : http://germanhistorydocs.ghi-dc.org/ sub_document.cfm?document_id=890

85. J.Peters, Dienstleistungsarbeit in der Industrie, VSA, 2000.

86. E. Black, IBM et l'Holocauste, Robert Laffont, 2001; E. Snowden, Intervention en France, Amnesty International, $2014:$ https://www.youtube.com/watch?v=o0nEJqThdmE

87. F.Granjon, op.cit., p.15. 
88. N.Fraser, La lutte pour l'interprétation des besoins in : Le féminisme en mouvements, La Découverte, 2013, p.82. Voir aussi Ferrarese/Neumann/Sagradini, entretien avec Nancy Fraser, « Pour une imagination radicale ", Variations, n 17, ed. Burozoïques, Paris, 2013, pp.12-20 http:// variations.revues.org/432

89. http://www.lemonde.fr/societe/article/2014/09/26/chez-gad-la-debrouillardise-desouvriers-illettres_4494846_3224.html

90. Adorno, Industriegesellschaft oder Spätkapitalismus? in : Aufsätze, Suhrkamp, 1970, pp.164-65.

91. Adorno, Negative Dialektik, Suhrkamp, 1997, pp.125-36.

92. "Désintégrer Heidegger", séminaire de recherche du cemti-Paris 8 dirigé par A.Neumann, été 2018; voir W. Benjamin, Briefe, III, Suhrkamp, 1997, p.522.

93. Adorno, Minima moralia. Reflexionen aus dem beschädigten Leben (Considérations depuis de la vie endommagée), Suhrkamp, 1951, pp. 480-81 (nous traduisons).

INDEX

Mots-clés : Ecole de Francfort, Théorie critique, Industrie culturelle, industrie de la culture, recherche sociale

\section{AUTEUR}

\section{ALEXANDER NEUMANN}

Professeur des Universités, Paris 8; directeur de la revue Variations 